\title{
General Perturbations Method for Orbit Lifetime Analysis Incorporating Non-Spherically-Symmetrical Atmospheres
}

\author{
Emma Kerr ${ }^{1}$ and Malcolm Macdonald ${ }^{2}$ \\ University of Strathclyde, Glasgow, Scotland, G1 1XJ
}

\begin{abstract}
A general perturbations method for orbit lifetime analysis is extended to include an analytical non-spherically-symmetrical atmospheric density model. This improvement allows the method to be applied with confidence to highly inclined orbits and special cases such as sun-synchronous orbits where the inclusion of the effects of atmospheric oblateness and the diurnal bulge will be particularly significant. These improvements can be applied to any general perturbations model for lifetime analysis. Using a case study of a sunsynchronous satellite a comparison is drawn between the original and improved methods, showing that by capturing the effects of a non-spherically-symmetrical atmosphere the orbit lifetime predicted could be up to $7 \%$ longer or $10 \%$ shorter than when using the sphericallysymmetrical model. Also notable is the difference between the orbit lifetime predictions made using the spherically-symmetrical model derived from different data sets; for the case study this was approximately a third of the orbit lifetime.
\end{abstract}

\section{Introduction}

$\mathrm{P}$ rimary body atmospheric friction, commonly referred to as atmospheric drag, is in general the largest contributor to satellite orbit decay in low Earth orbit (below $1000 \mathrm{~km}$ ) as it acts against the velocity vector retarding the satellite resulting in a reduction in the orbit energy. The magnitude of the force created by drag is directly proportional to the atmospheric density at the orbit altitude. ${ }^{1}$ However this property is notoriously difficult to predict as the atmosphere varies in shape and size due to many effects including, but not limited, to solar activity, geomagnetic activity, atmospheric oblateness and time-dependent variations such as the semi-annual variation and the diurnal variation. The omission of these effects means that special cases such as polar and sun-synchronous satellites cannot be assumed to be accurately modeled using a spherically-symmetrical model of the atmosphere as the high inclination and very slow right ascension drift could cause the orbit to experience an abnormal atmospheric density.

Two deviations from the spherically-symmetrical atmosphere are discussed herein; atmospheric oblateness and the diurnal variation. Atmospheric oblateness is the term used to describe the bulge in the atmosphere centered on the equator; this bulge is caused by the oblateness of the Earth. ${ }^{2}$ The diurnal variation is the variation in atmospheric density caused by the relative position of the sun. When the sun is overhead, i.e. when local mean solar time is midday the atmosphere expands. The relative motion of the Earth and sun means that this bulge is not always in the same location over the Earth. ${ }^{2}$

General perturbations methods (colloquially known as analytical methods) for orbit lifetime analysis have been widely discussed, and the authors have previously presented a method derived from that presented by Cook, KingHele and Walker. ${ }^{3,4}$ The authors have also presented methods of incorporating a projected area model, an analytical atmospheric density model and a solar activity model into the general perturbations method developed and a method of incorporating current decay data to improve orbit lifetime predictions made using the method developed. ${ }^{5-8}$ When validated against historical mission data, the method developed with its various additions has been shown to improve the accuracy of previous methods, such as those presented by King-Hele, from around 50\% error to within $5 \%$ in some cases. However the authors' previous work has focused solely on a spherically-symmetrical atmosphere, neglecting the effects of atmospheric oblateness and the diurnal variation.

\footnotetext{
${ }^{1}$ Ph.D. Candidate, Mechanical \& Aerospace Engineering, James Weir Building, 75 Montrose Street, Glasgow, G1 1XJ, AIAA Student Member.

${ }^{2}$ Reader, Mechanical \& Aerospace Engineering, James Weir Building, 75 Montrose Street, Glasgow, G1 1XJ, AIAA Associate Fellow.
} 
Various attempts have been made to include the effects of atmospheric oblateness and the diurnal variation in general perturbations analysis. Studies completed by Cook, King-Hele and Walker showed that modifications could be made to orbit lifetime equations to account for these effects. ${ }^{9-12}$ Swinerd and Boulton completed a similar study, this study included both oblateness and the diurnal variation. ${ }^{13}$ Sharma completed comparable studies using K-S elements in place of the power series expansions of semi-major axis, eccentricity and Eccentric anomaly used in Cook, King-Hele and Walker's publications. ${ }^{14-17}$ However to the authors' knowledge no attempt has been made to separate the effects into a simple analytical atmospheric density model which could be applied to any general perturbations model. Therefore this paper addresses the addition of atmospheric oblateness and the diurnal variation to the analytical density model previously derived by the authors. ${ }^{5,6}$

To incorporate the effect of atmospheric oblateness and the diurnal effect a slightly more complex analytical atmospheric density model is required. The previous model presented by the authors required two simple inputs: the density index (the parameter used to describe the effect of solar activity) and the altitude. ${ }^{5,6} \mathrm{~A}$ model including atmospheric oblateness requires the addition of inclination to the inputs and a model incorporating the diurnal variation requires the addition of the local mean solar time. The addition of these effects makes the model more complex.

\section{Atmosphere Model}

The authors have previously presented an analytical atmosphere model based on the total atmospheric density data from the Committee on Space Research International Reference Atmosphere, commonly known as CIRA or CIRA-12. ${ }^{18}$ However this model did not account for the effect of atmospheric oblateness and the diurnal bulge. The CIRA total density data used to derive the previous model is not time-variant therefore a new data set is required to build an analytical model for atmospheric density given the local solar time and inclination. Therefore, using a data set taken from the Naval Research Laboratory Mass Spectrometer and Incoherent Scatter Radar Exosphere 2000 (commonly known as NRLMSISE-00 or NRLMSISE) model, the same method of derivation was used to build a new model. ${ }^{19}$ In the authors previous study the NRLMSISE data was rejected as it was shown by Chao et al. that NRLMSISE had large discrepancies. ${ }^{20}$ However it is currently the most accurate data available which includes the time-variance required for the method presented herein. The method of derivation presented herein could be applied to any data set.

In order to study the influence of each effect they are studied separately. First however the previous analytical model for atmospheric density derived by the authors is re-derived using the NRLMSISE data set in place of the CIRA data. This will allow for a fair comparison of the influence of each of the effects studied. A comparison of the spherically-symmetrical analytical models will also be drawn.

\section{A. Spherically-Symmetrical Analytical Atmospheric Density Model}

As in the authors' previous work, curve fitting was used to find an equation that fit the NRLMSISE-00 data. As in the previous work three solar activity states are taken as the baseline for the model, the density index (an index used to describe the solar activity state) discussed in $\left.{ }^{5,6}\right]$ can then be used to interpolate between these three states. For the purpose of this paper these three states refer to three specific days on which the atmospheric density is studied, these days are the $1^{\text {st }}$ of January 2008 , the $1^{\text {st }}$ January 2002 and the $1^{\text {st }}$ of January 2015 . These dates experienced low, moderate and high solar activity states respectively with mean solar activity levels of 70, 140 and 230 respectively. None of these dates experienced significant solar or geomagnetic storm events as far as the authors are aware.

As the model is position and time dependent the latitude, longitude and local mean solar time were averaged out for each date before the curve fitting for the spherically-symmetrical model is carried out. This was done by taking the average of all the data points for time through the day and for all data points through latitude and longitude. This averaging gives the mean atmospheric density for each altitude on each of the three dates studied.

It was found that, as with the CIRA data, a power curve fit was the most descriptive of the data. Therefore it was chosen to build the model. The equation of this power curve is

$$
\rho=a h^{b}
$$

where $\rho$ is the total atmospheric density, $\mathrm{h}$ is altitude and $\mathrm{a}$ and $\mathrm{b}$ are constants dependent on the solar activity state. A set of very simple curve fits using just one equation to fit all the data for each solar activity state was first derived and is shown in Figure 1. The coefficients for Eq. (1) used to produce the curve fits displayed in Figure 1 are shown in Table 1. 


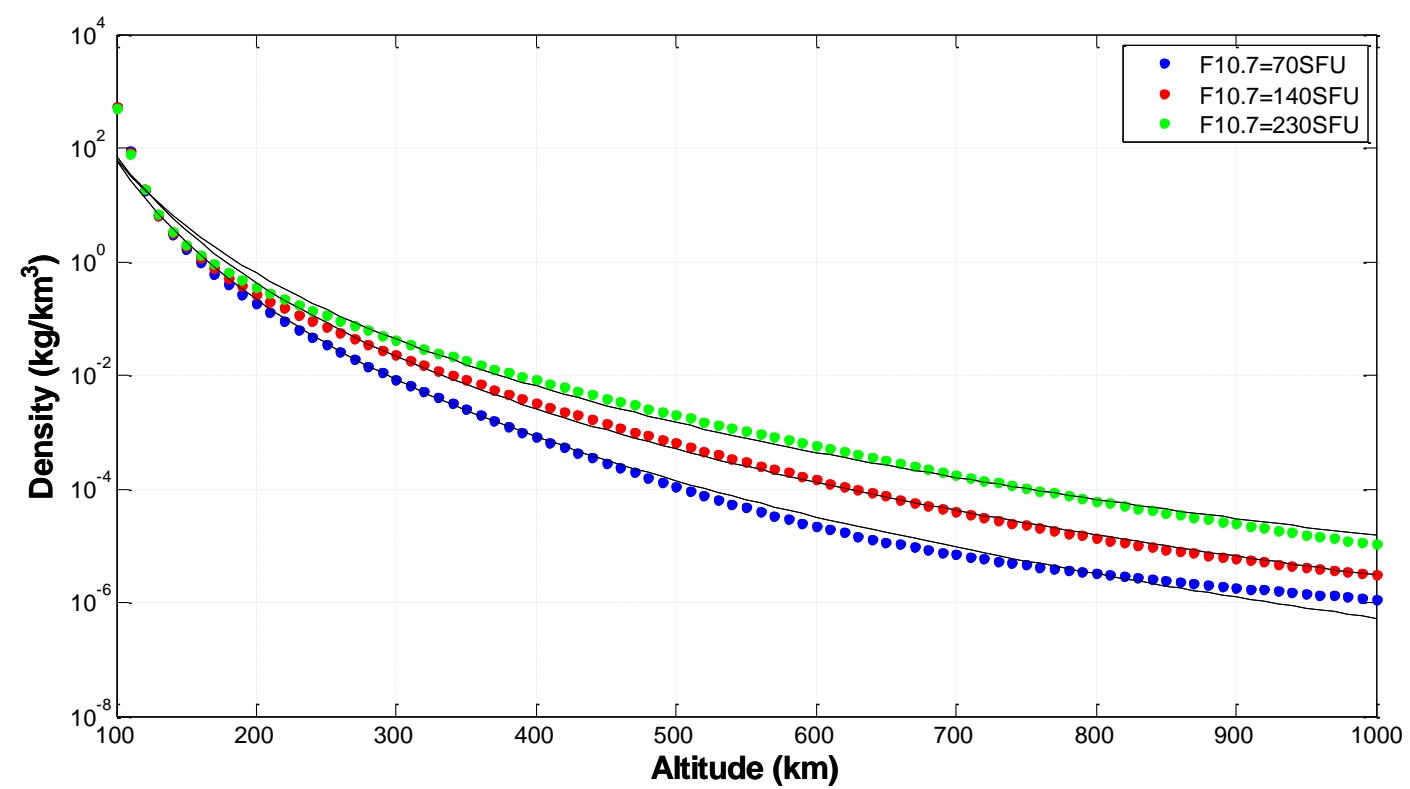

Figure 1. Power curve fit for mean atmospheric density at given solar activity levels using single curves (N.B. logarithmic y-axis)

Table 1. Coefficients for Eq. (1)

\begin{tabular}{lcccccc}
\hline & \multicolumn{2}{c}{$\begin{array}{c}\text { Low Solar Activity } \\
\mathbf{F}_{\mathbf{1 0 . 7}}=\mathbf{7 0 S F U}\end{array}$} & \multicolumn{2}{c}{$\begin{array}{c}\text { Moderate Solar Activity } \\
\mathbf{F}_{\mathbf{1 0 . 7}}=\mathbf{1 4 0 S F U}\end{array}$} & \multicolumn{2}{c}{ High Solar Activity } \\
$\mathbf{F}_{\mathbf{1 0 . 7}}=\mathbf{2 3 0 S F U}$
\end{tabular}

It can be seen in Figure 1 that the use of one curve is not particularly efficient at describing the data over the full range of altitudes. Therefore the data was broken into small subsets of approximately $100 \mathrm{~km}$ each, each set having its own curve fit. Figure 2 shows this multi-curve fit. 


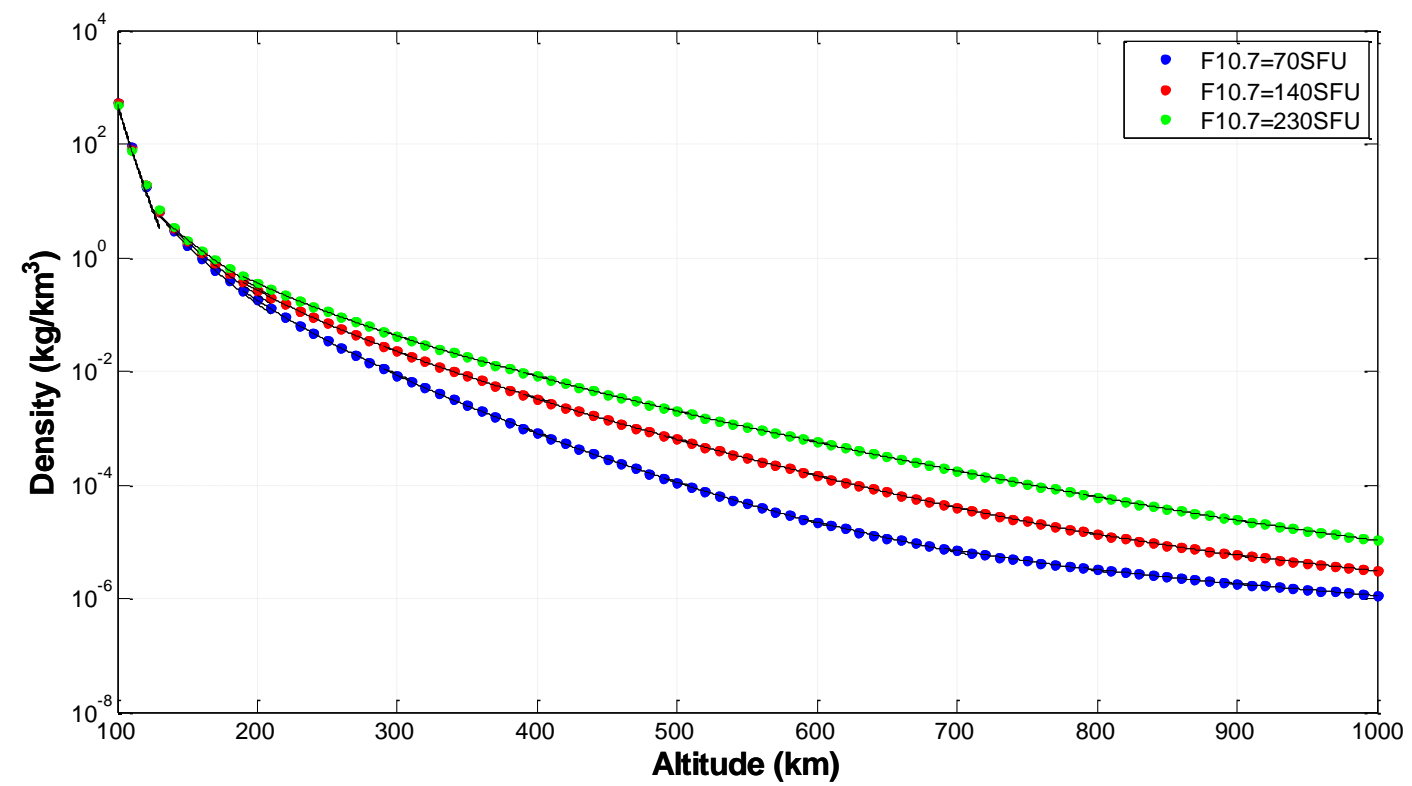

Figure 2. Power curve fit for mean atmospheric density at given solar activity levels using multiple curves (N.B. logarithmic y-axis)

Table 2. Coefficients for Eq. (1)

\begin{tabular}{|c|c|c|c|c|c|c|}
\hline \multirow[t]{2}{*}{ Altitude Range } & \multicolumn{2}{|c|}{$\begin{array}{c}\text { Low Solar Activity } \\
\text { F }_{10.7}=70 S F U\end{array}$} & \multicolumn{2}{|c|}{$\begin{array}{l}\text { Moderate Solar Activity } \\
\qquad \mathrm{F}_{10.7}=140 \mathrm{SFU}\end{array}$} & \multicolumn{2}{|c|}{$\begin{array}{l}\text { High Solar Activity } \\
\mathrm{F}_{10.7}=230 \mathrm{SFU}\end{array}$} \\
\hline & $a$ & $b$ & $a$ & $b$ & $a$ & $b$ \\
\hline $100-140 \mathrm{~km}$ & $6.329 \mathrm{E}+40$ & -19.036 & $7.201 \mathrm{E}+40$ & -19.073 & $9.232 \mathrm{E}+40$ & -19.138 \\
\hline $140-200 \mathrm{~km}$ & $1.815 \mathrm{E}+18$ & -8.286 & $3.125 E+16$ & -7.452 & $1.552 \mathrm{E}+15$ & -6.830 \\
\hline $200-300 \mathrm{~km}$ & $1.965 \mathrm{E}+16$ & -7.403 & $2.887 \mathrm{E}+13$ & -6.097 & $4.729 \mathrm{E}+11$ & -5.266 \\
\hline $300-400 \mathrm{~km}$ & $5.434 \mathrm{E}+17$ & -7.994 & $3.184 \mathrm{E}+14$ & -6.521 & $3.145 \mathrm{E}+12$ & -5.600 \\
\hline $400-500 \mathrm{~km}$ & $5.240 \mathrm{E}+19$ & -8.767 & $1.793 \mathrm{E}+16$ & -7.201 & $1.272 \mathrm{E}+14$ & -6.222 \\
\hline $500-600 \mathrm{~km}$ & $2.095 \mathrm{E}+20$ & -8.995 & $1.331 \mathrm{E}+18$ & -7.901 & $4.179 \mathrm{E}+15$ & -6.788 \\
\hline $600-700 \mathrm{~km}$ & $2.286 \mathrm{E}+17$ & -7.924 & $2.121 \mathrm{E}+19$ & -8.338 & $1.676 \mathrm{E}+17$ & -7.370 \\
\hline $700-800 \mathrm{~km}$ & $2.245 \mathrm{E}+12$ & -6.152 & $9.538 \mathrm{E}+18$ & -8.217 & $2.998 \mathrm{E}+18$ & -7.813 \\
\hline $800-900 \mathrm{~km}$ & $1.085 \mathrm{E}+09$ & -5.002 & 4.377E+16 & -7.408 & $1.108 \mathrm{E}+19$ & -8.010 \\
\hline $900-1000 \mathrm{~km}$ & $6.120 \mathrm{E}+07$ & -4.577 & $2.076 \mathrm{E}+13$ & -6.277 & $4.072 \mathrm{E}+18$ & -7.863 \\
\hline
\end{tabular}

It can be seen that the use of multiple curves to fit the data significantly improves the description of the data. Therefore the multi-curve fit is used moving forward. However it can be seen that the transition between curves at lower altitudes can be problematic. As such the subsets in this region are smaller than those at higher altitudes and the curves are extended to find the points of intersection, which are then used as the transition to avoid discontinuities in the model.

\section{B. Atmospheric Oblateness}

Atmospheric oblateness is caused by the Earth's oblateness, the bulge of the Earth around the equator. As a satellite passes over the equatorial bulge the effective altitude of that satellite is less than that of a satellite with the same semi-major axis passing over the North or South Pole. This differential in effective altitude means that the density experienced is greater for the satellite over the equator than the satellite over the Pole.

\section{4}

American Institute of Aeronautics and Astronautics 
The data used to study atmospheric oblateness is the same data used to generate the spherically-symmetrical analytical density model discussed in the previous section. However to study the oblateness the data is averaged over longitude and time to remove the effect of the diurnal variation. This leaves a 3D data set, for each solar activity state, for the atmospheric density at a given altitude and latitude. When studied it was found that the effect of oblateness is only present in the very low altitudes. Figure 3 shows the variation caused by atmospheric oblateness for low solar activity. This figure has been reproduced for moderate and high solar activity states, these figures can be seen in Appendix A. It can be seen in Figure 3 that the effect of atmospheric oblateness is only present below $120 \mathrm{~km}$ and, as the orbit lifetime analysis method developed by the authors is intended for use for much longer lifetimes than would occur at these altitudes, this effect is deemed negligible in terms of this work.

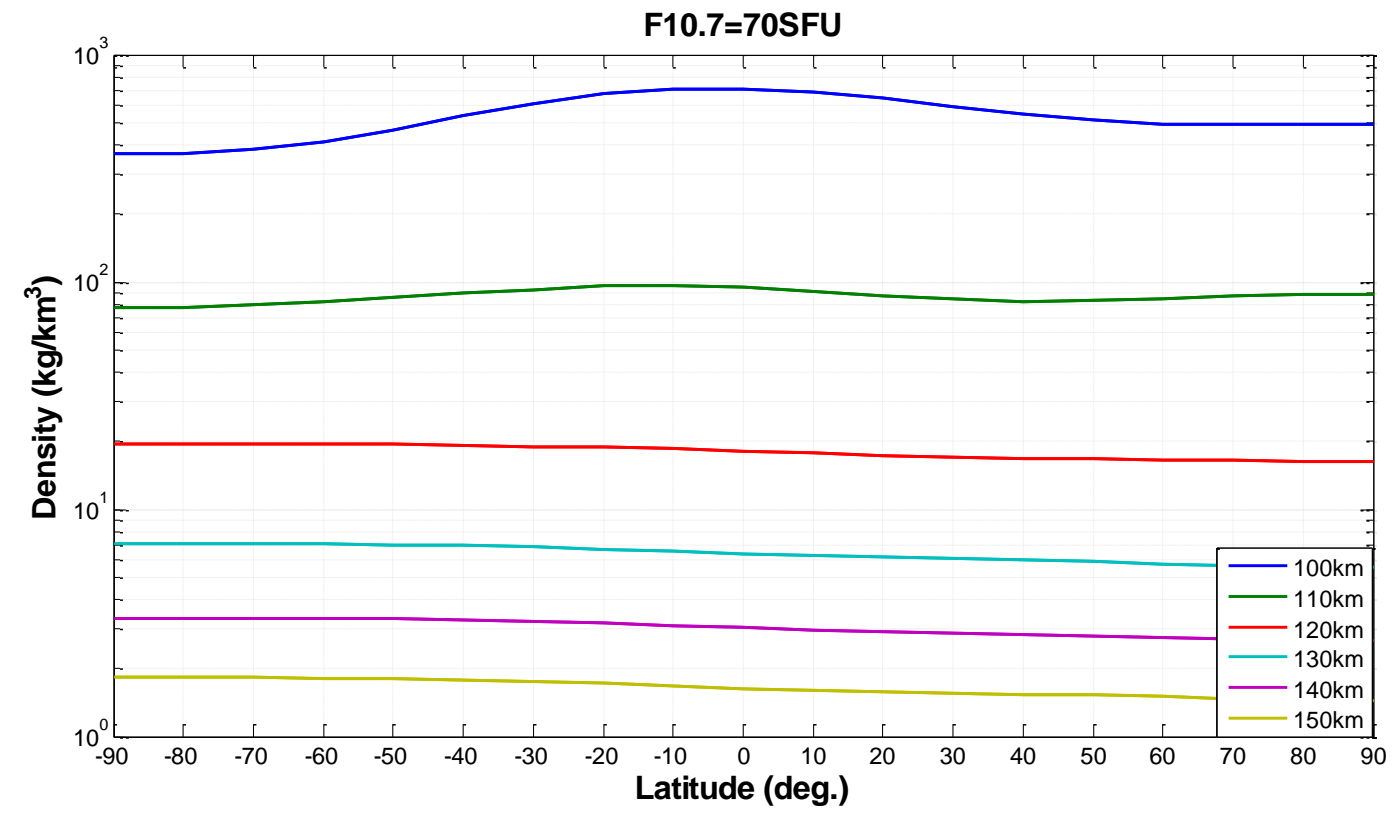

Figure 3. Atmospheric oblateness at low solar activity (N.B. logarithmic y-axis)

\section{Diurnal Variation}

The diurnal variation is the bulge in the atmosphere occurring when the sun is overhead. The diurnal variation occurs every day as the Earth rotates, as the sun and Earth move in relation to each other the position of the effect varies, but generally the variation occurs at approximately the same local mean solar time every day. Namely being that as the sun is overhead the atmosphere directly in line with the sun experiences heating while the atmosphere on the opposite side of the planet experiences cooling leaving the atmosphere with a pronounced bulge on one side. This effect lags slightly behind the sun, with the maximum density occurring at approximately $2-3 \mathrm{pm}$ local solar time.

The data used to study the diurnal variation again had to be averaged over latitude to neglect the effect atmospheric oblateness. In this case the data set is a 4D set giving the atmospheric density at a given solar activity level, altitude and local mean solar time. For each solar condition, as discussed in Section II.A, this data can be represented by a 3D surface, as shown in Figure 4. Note, in Figure 4 when the difference from mean density is positive the density given by the model including the diurnal variation is greater than that given by the sphericallysymmetrical model. 


\section{F10.7=70SFU}

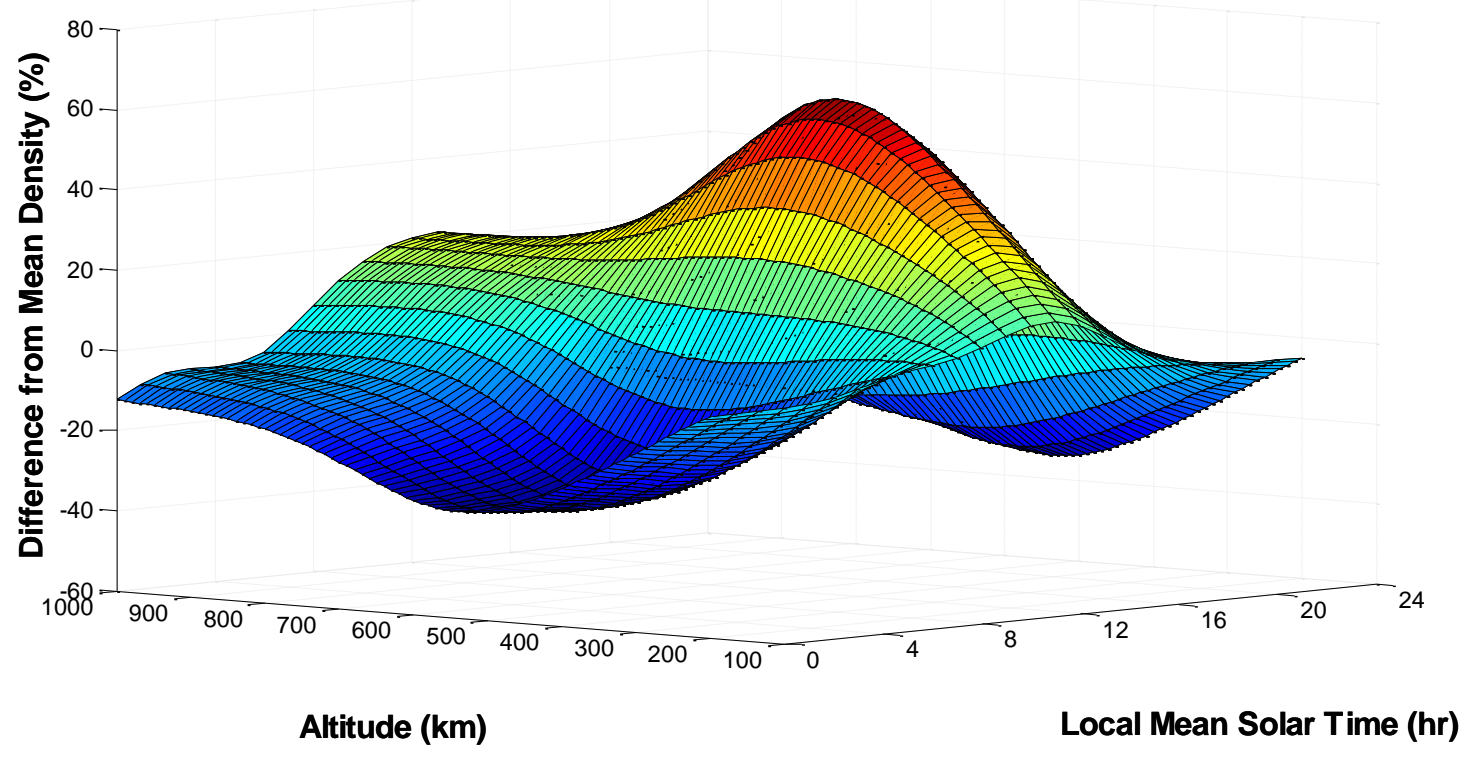

Figure 4. 3D surface describing density variation at low solar activity due to the diurnal variation

As this surface is quite complex to simplify the analysis the surface can be described by a series of curves for the difference from the mean atmospheric density through a solar day given a specific altitude as can be seen in Figure 5 .

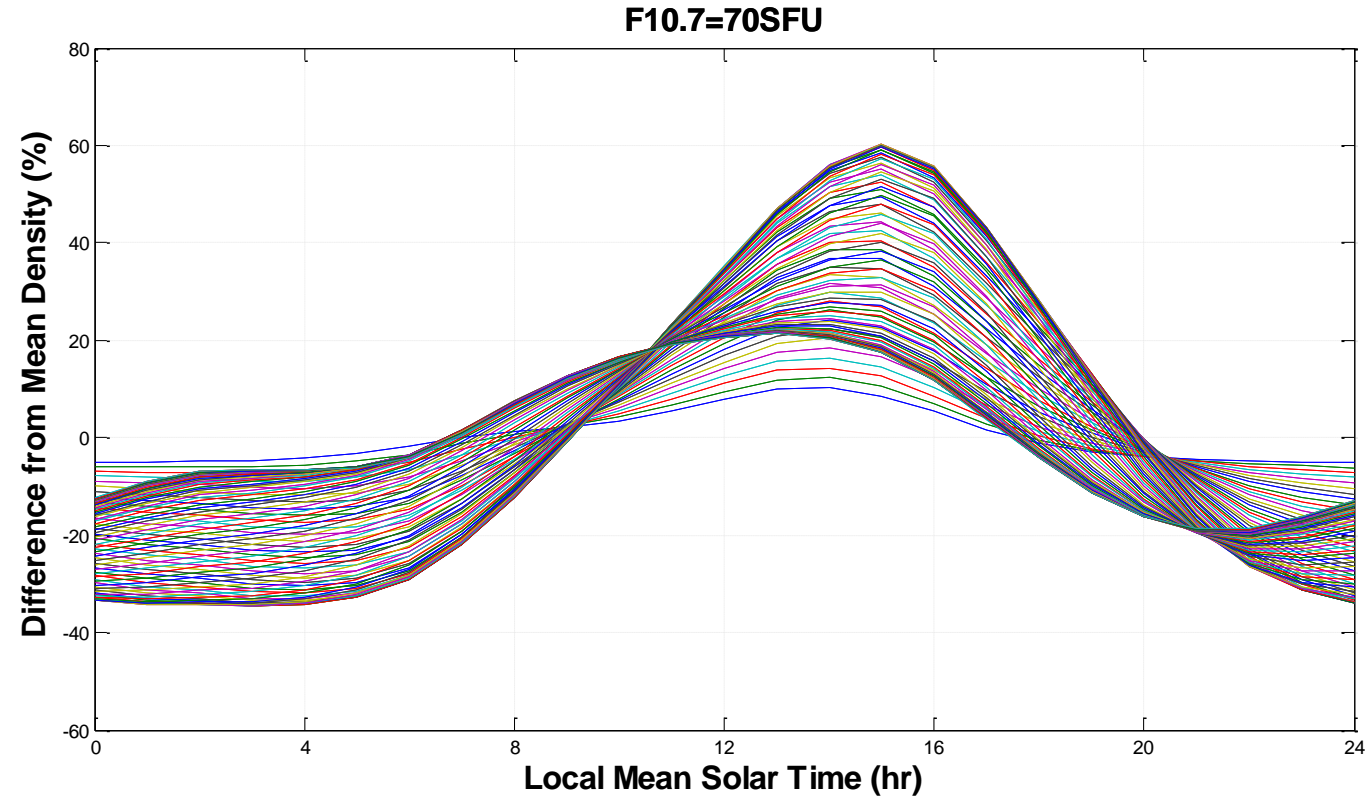

Figure 5. Altitude specific curves describing density variation at low solar activity due to the diurnal variation

Each of the discrete curves shown in Figure 5 can be described by a single equation of the form

$$
\% \text { Diff }=p_{1} t^{8}+p_{2} t^{7}+p_{3} t^{6}+p_{4} t^{5}+p_{5} t^{4}+p_{6} t^{3}+p_{7} t^{2}+p_{8} t+p_{9}
$$


where $p_{1-9}$ are variable coefficients of the curve whose value is dependent on altitude and $t$ is the local mean solar time. The relationship between each of these curves can be described by analyzing the relationship between the coefficients of the individual altitude curves.

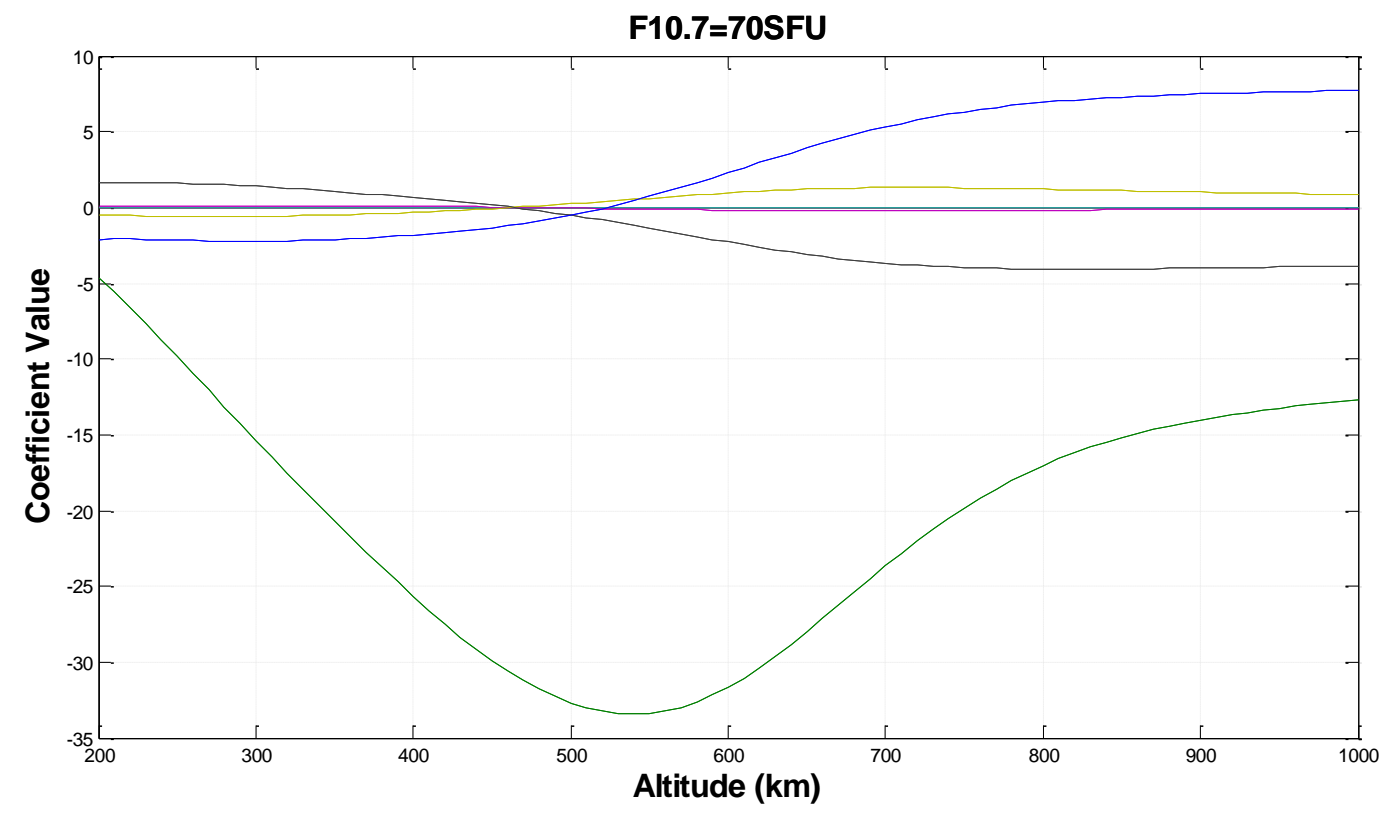

Figure 6. Variation due to altitude of coefficients for altitude specific curves from Figure 5

As can be seen in Figure 6 there is a clear relationship between the coefficients and altitude. Therefore each coefficient can be determined using the equation of the relationship between altitude and coefficient value. These equations were determined using curve fitting. Each coefficient from Eq. (2) can be described by an equation of the form

$$
p_{1}=c_{1} h^{8}+c_{2} h^{7}+c_{3} h^{6}+c_{4} h^{5}+c_{5} h^{4}+c_{6} h^{3}+c_{7} h^{2}+c_{8} h+c_{9}
$$

where $c_{1-9}$ are constants and $h$ is altitude. A simpler form of equation, for example a smaller order polynomial, could be used in place of Eq. (2) and (3) to reduce the number of constants required. However for the purposes of this paper it was decided to use the most accurate fit and thereby more constants. This process was carried out for each solar activity state and Figure 4, Figure 5 and Figure 6 have been reproduced for each state and are shown in Appendix B. A full list of the constants determined and used in this paper is shown in Appendix C.

\section{Application of Atmospheric Model including Diurnal variation to Orbit Lifetime Analysis}

In order to demonstrate the modifications made to the analytical atmospheric model the authors' general perturbations solution is used. In general perturbations methods for orbit lifetime analysis a single density value is used to calculate the orbit lifetime. This density value is, in general, the total atmospheric density at the orbit periapsis. When considering the atmosphere model including the diurnal variation this single value may not be representative of the density over the orbit lifetime. For example if the density is taken at a local mean solar time of 12 noon, the density will be much greater than if it was taken at 12 midnight. Therefore it is recommended that when using general perturbations methods the density used should be an average taken over the first orbit. The variation of density over an orbit is dependent on the variation in local mean solar time. This variation is not constant but its rate of change can be linked to the inclination. Figure 7 demonstrates the relationship between local mean solar time and inclination. 


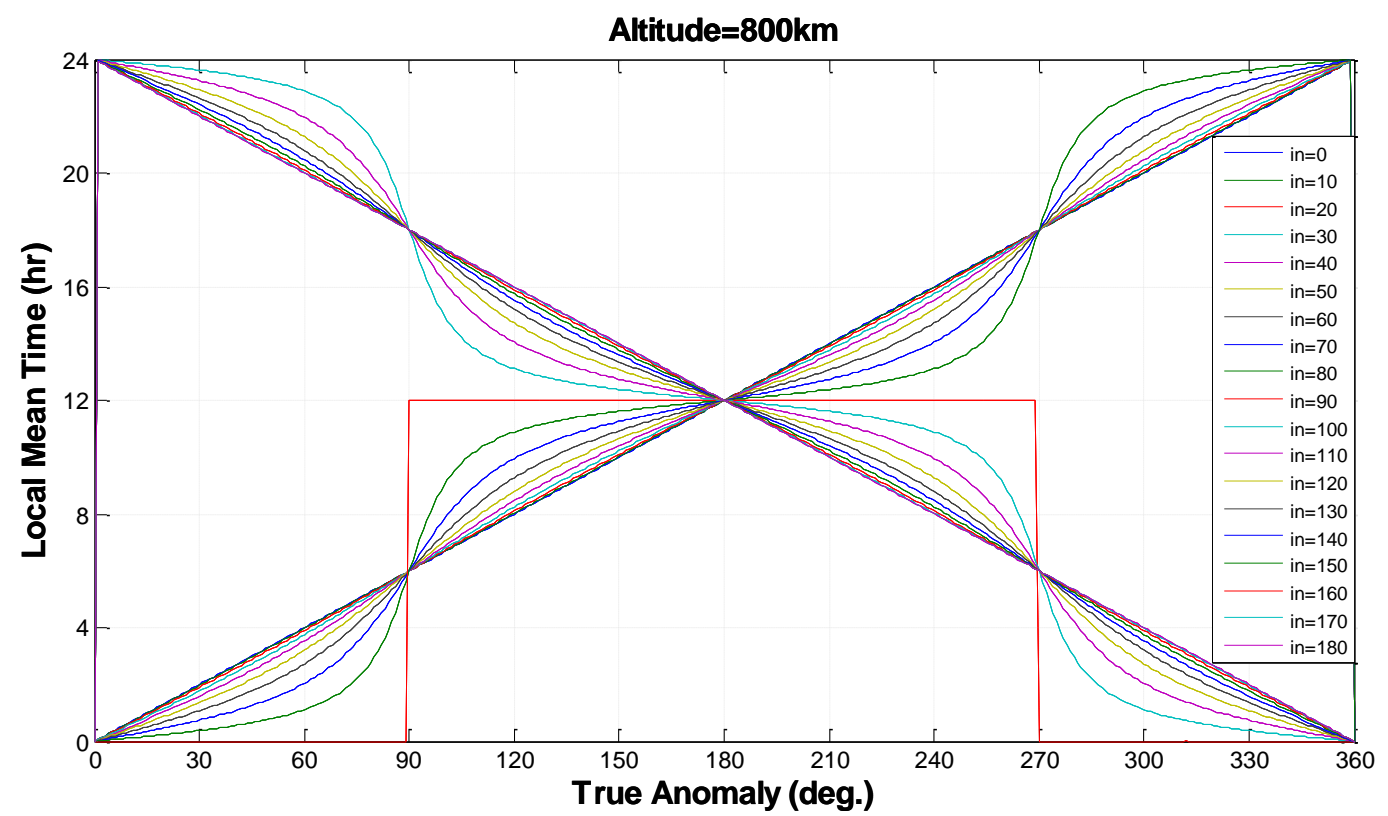

Figure 7. Relationship between inclination and local mean time for a satellite in an orbit of altitude $=800 \mathrm{~km}$

It can be seen in Figure 7 that satellites in polar orbits experience an instantaneous shift in solar time between noon and midnight. It should be noted however that Figure 7 is generated for a particular orbit, on a particular date, starting at a particular time. Therefore this noon-midnight paradigm could be $2 \mathrm{am}-2 \mathrm{pm}$ given a different initial date and time. The pattern visible would remain the same, however it would be shifted in the y-axis. This variation in local solar time can then be mapped to the variation in density, as can be seen in Figure 8. Again it should be noted that Figure 8 is accurate only for this particular orbit, date and time. This figure has been reproduced for each solar activity state and is shown in Appendix D.

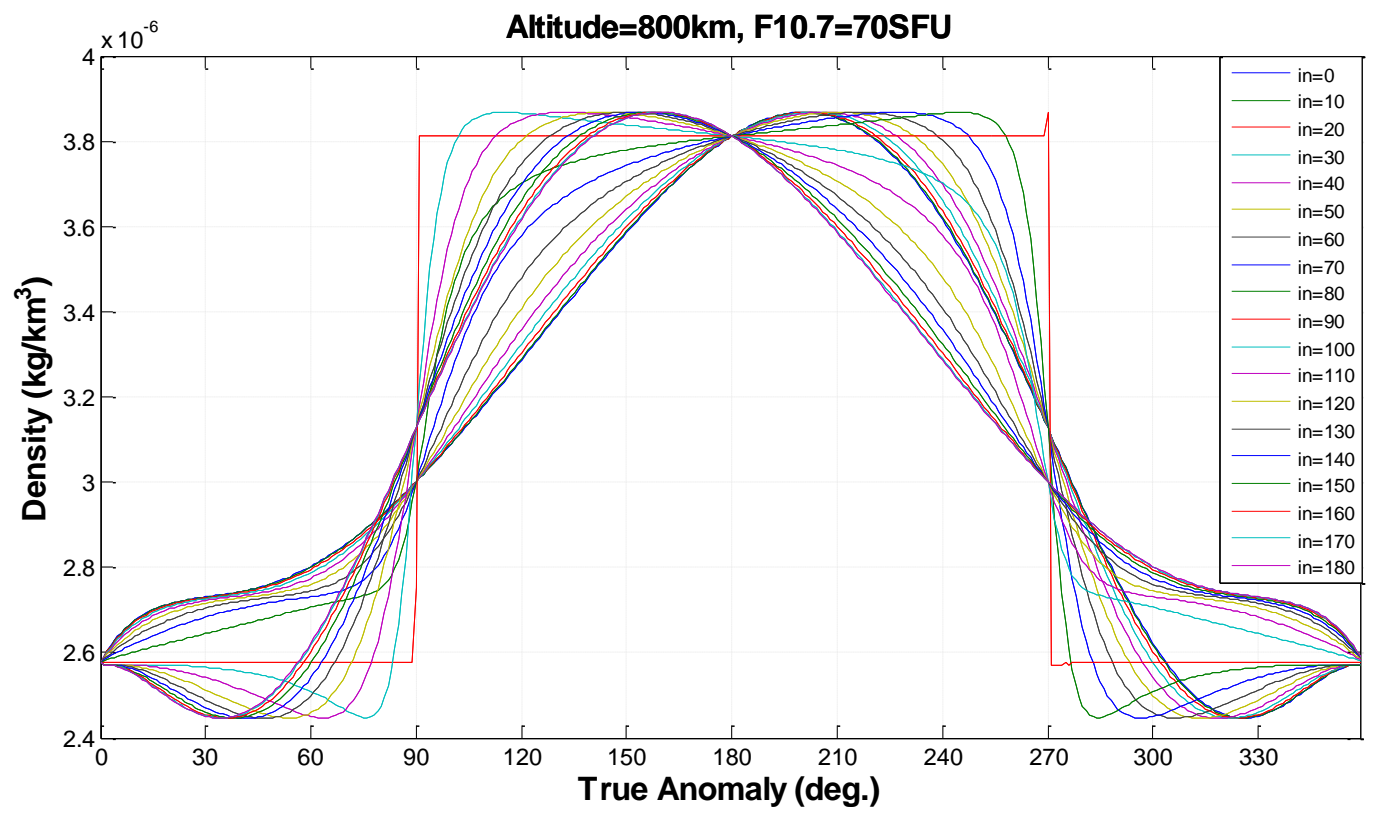

Figure 8. Change in density over 1 orbit revolution due to the diurnal variation for a satellite at $800 \mathrm{~km}$ altitude and various inclinations 
Using the method of averaging for one orbit revolution the difference in the mean density when using the diurnal model instead of the mean density from the spherically-symmetrical model as discussed in Section II.A can be calculated. This error is plotted for various inclinations and orbit altitudes in Figure 9.

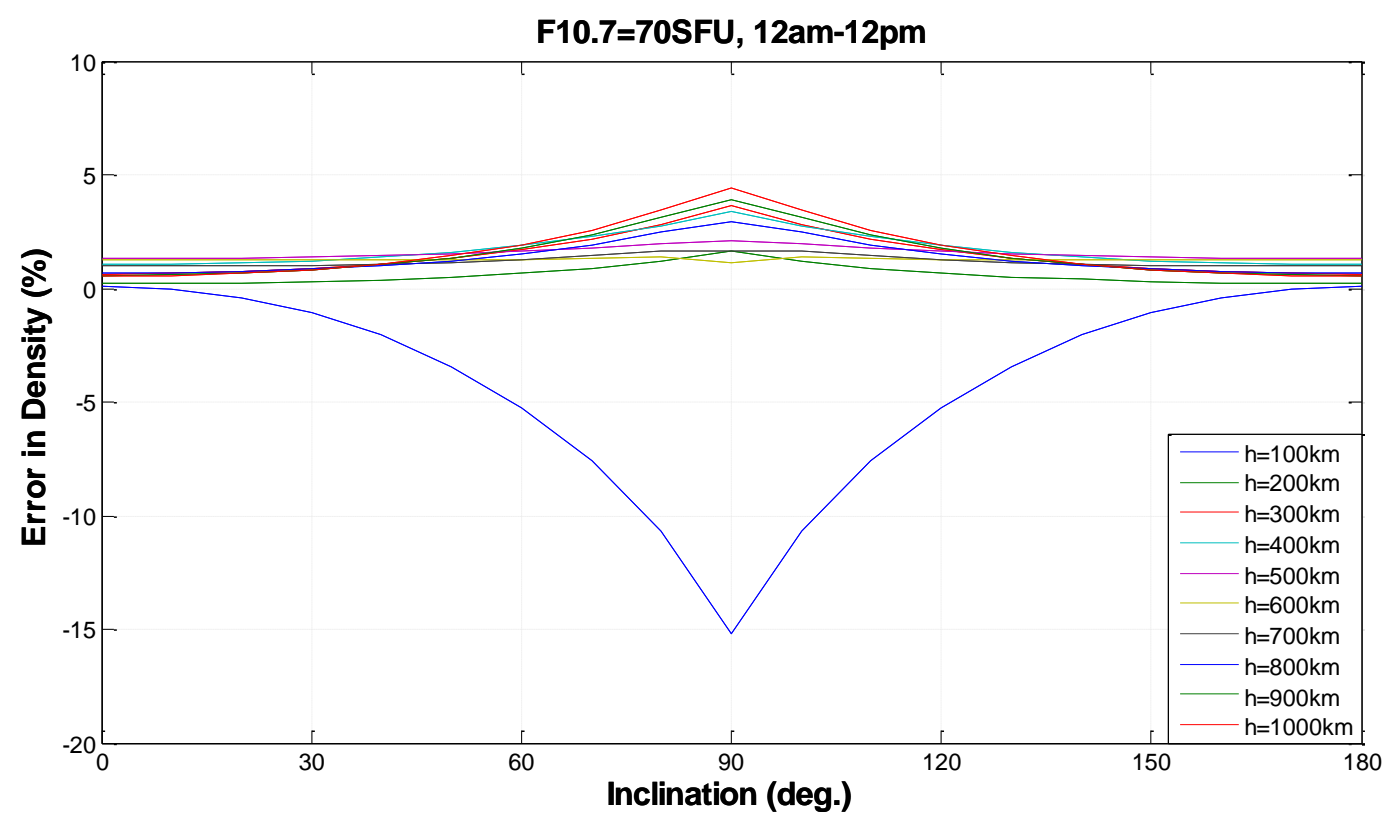

Figure 9. Error in density when comparing the mean density given by the diurnally varying atmospheric model and the mean density from the spherically-symmetrical atmospheric model for a 12am-12pm orbit

Figure 9 shows that the peak in density error occurs for polar orbits where inclination $=90^{\circ}$. It also shows that for the majority of altitudes the spherically-symmetrical atmosphere model is underestimating the density, while at lower altitudes the spherically-symmetrical model is seriously overestimating the density. This figure has been reproduced for each solar activity state and is shown in Appendix E. The pattern over and under-estimating the density is consistent across the solar activity levels, as can be seen in the figures in Appendix E. As with Figure 7 and Figure 8, it should be noted that Figure 9 is only accurate for the particular date and time used to create it; however this gives an idea of the errors which are carried into the orbit lifetime analysis. It was found that the mean errors occur when the satellite is in a noon-midnight or 6am-6pm orbit. The maximum errors occur in 9am-9pm and $3 \mathrm{am}-3 \mathrm{pm}$ orbits. For $9 \mathrm{am}-9 \mathrm{pm}$ orbits the spherically-symmetrical atmosphere model seriously underestimates the density for higher altitudes, while for the $3 \mathrm{am}-3 \mathrm{pm}$ orbits the spherically-symmetrical atmosphere model seriously overestimates the density for higher altitudes. Figure 10 and Figure 11 show the errors for the $9 \mathrm{am}-9 \mathrm{pm}$ and $3 \mathrm{am}-$ $3 \mathrm{pm}$ orbits respectively. 


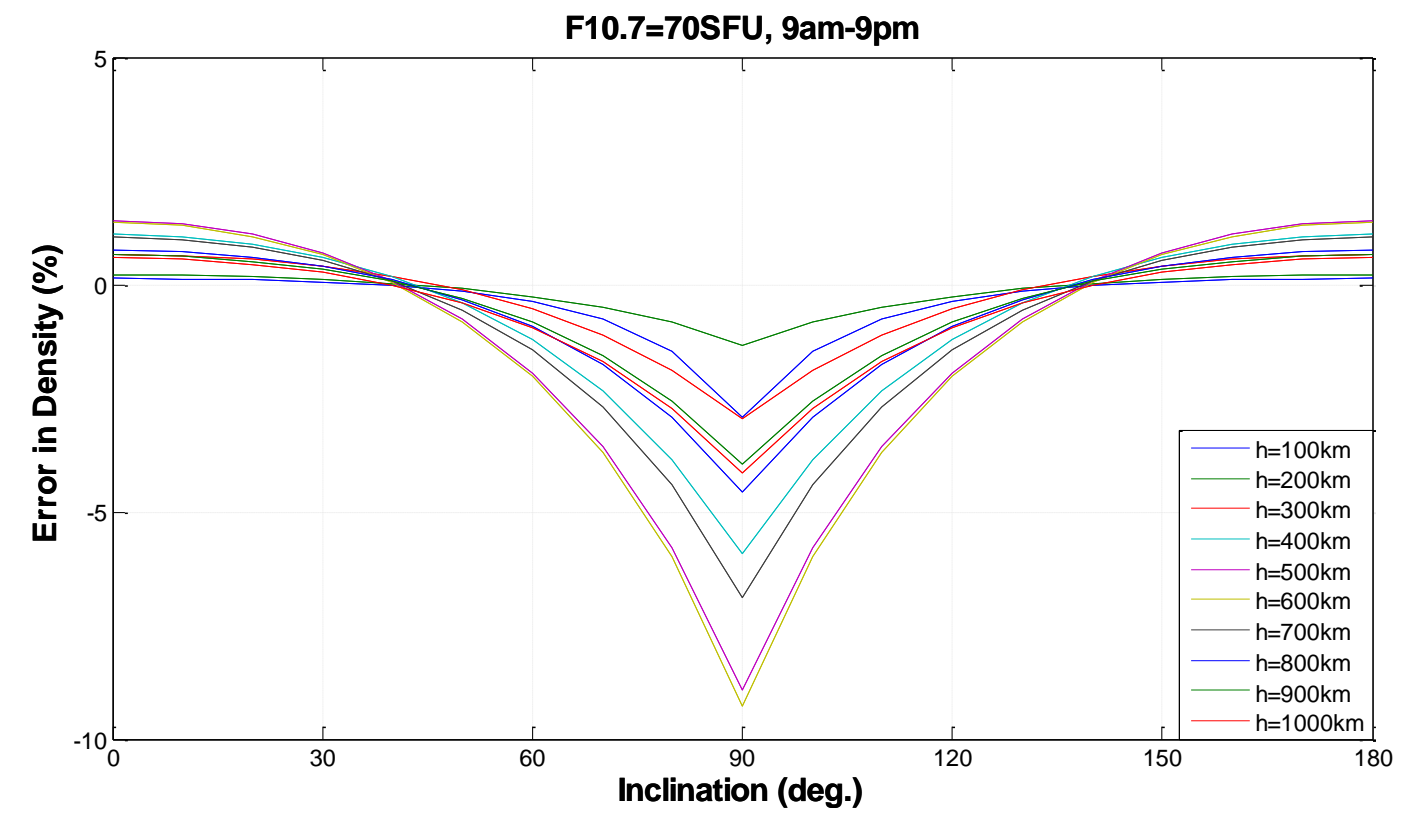

Figure 10. Error in density when comparing the mean density given by the diurnally varying atmospheric model and the mean density from the spherically-symmetrical atmospheric model for a 9am-9pm orbit

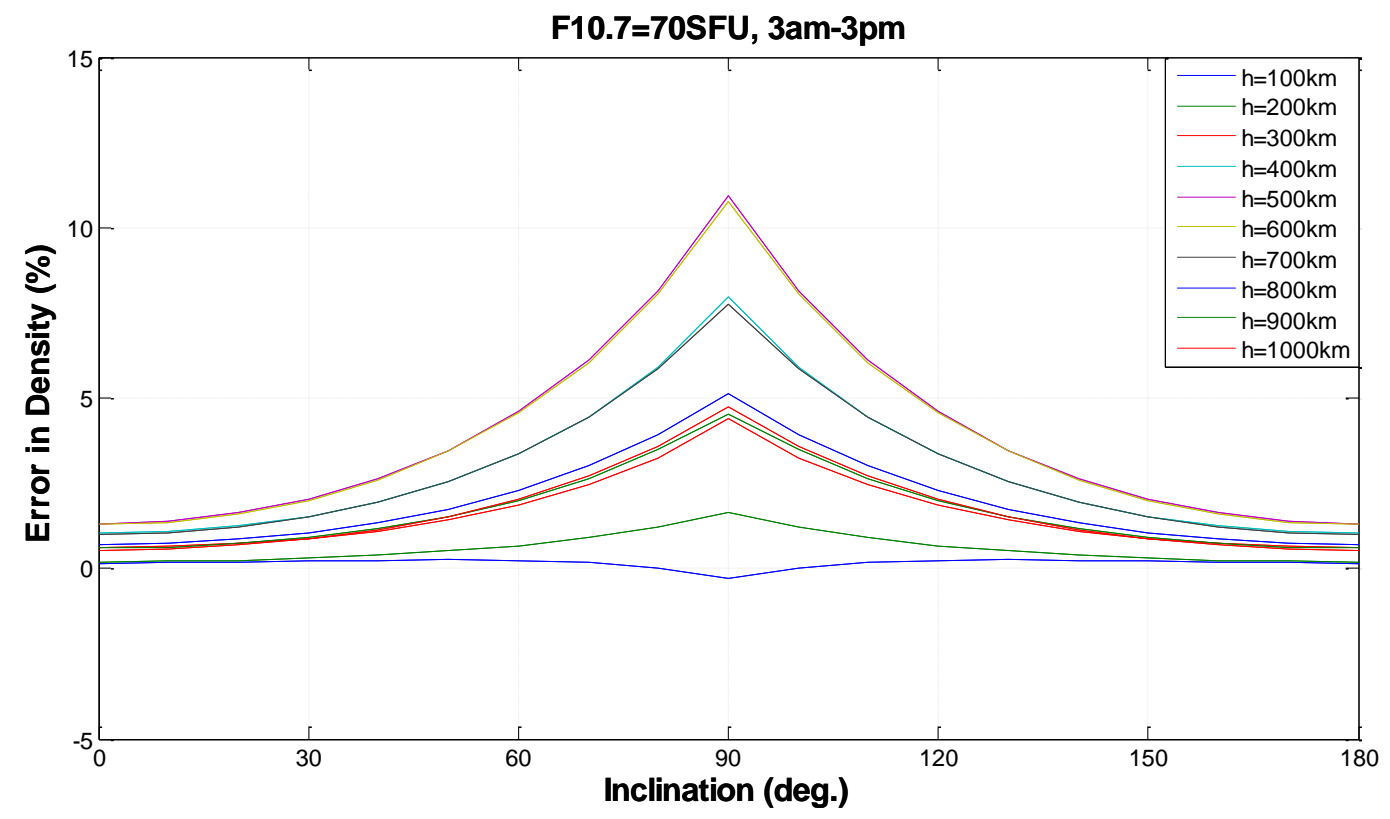

Figure 11. Error in density when comparing the mean density given by the diurnally varying atmospheric model and the mean density from the spherically-symmetrical atmospheric model for a $3 \mathrm{am}-3 \mathrm{pm}$ orbit

The importance of the position of the orbit is particularly significant when considering a sun-synchronous satellite. The right ascension of the ascending node of a sun-synchronous satellite rotates at the same rate as the Earth meaning that it maintains its orbit position relative to the Earth, i.e. if the orbit starts as a noon-midnight orbit it will remain as such until the satellite loses a significant amount of altitude such that its right ascension begins to drift at a different rate to the Earth's surface. 
As the orbit lifetime calculated using the authors general perturbations model is directly proportional to the density, any error in the density is translated directly into an error in the lifetime analysis, therefore the inclusion of the diurnal variation is very important when considering sun-synchronous satellites.

\section{Case Study}

In order to demonstrate the significance of including the diurnally varying density model in the orbit lifetime analysis a case study is carried out using a sun-synchronous satellite. The spacecraft and orbit parameters for this case study are contained in Table 3. Note the right ascension of the ascending node is not given in as it was allowed to vary between 0 and $360^{\circ}$ to show the variation this parameter makes in the orbit lifetime prediction. Figure 12 shows the predictions made given the parameters shown in Table 3.

Table 3. Case Study Spacecraft and Orbit Parameters

\begin{tabular}{lc}
\hline Parameter & Value \\
\hline Epoch & $1^{\text {st }}$ January $201600: 00: 00$ \\
Mass & $1 \mathrm{~kg}$ \\
Projected Area & $1 \mathrm{~m}^{2}$ \\
Drag Coefficient & 2.2 \\
Altitude & $800 \mathrm{~km}$ \\
Eccentricity & 0 \\
Inclination & $98.6^{\circ}$ \\
Argument of Perigee & $0^{\circ}$ \\
Mean Anomaly & $0^{\circ}$ \\
\hline
\end{tabular}

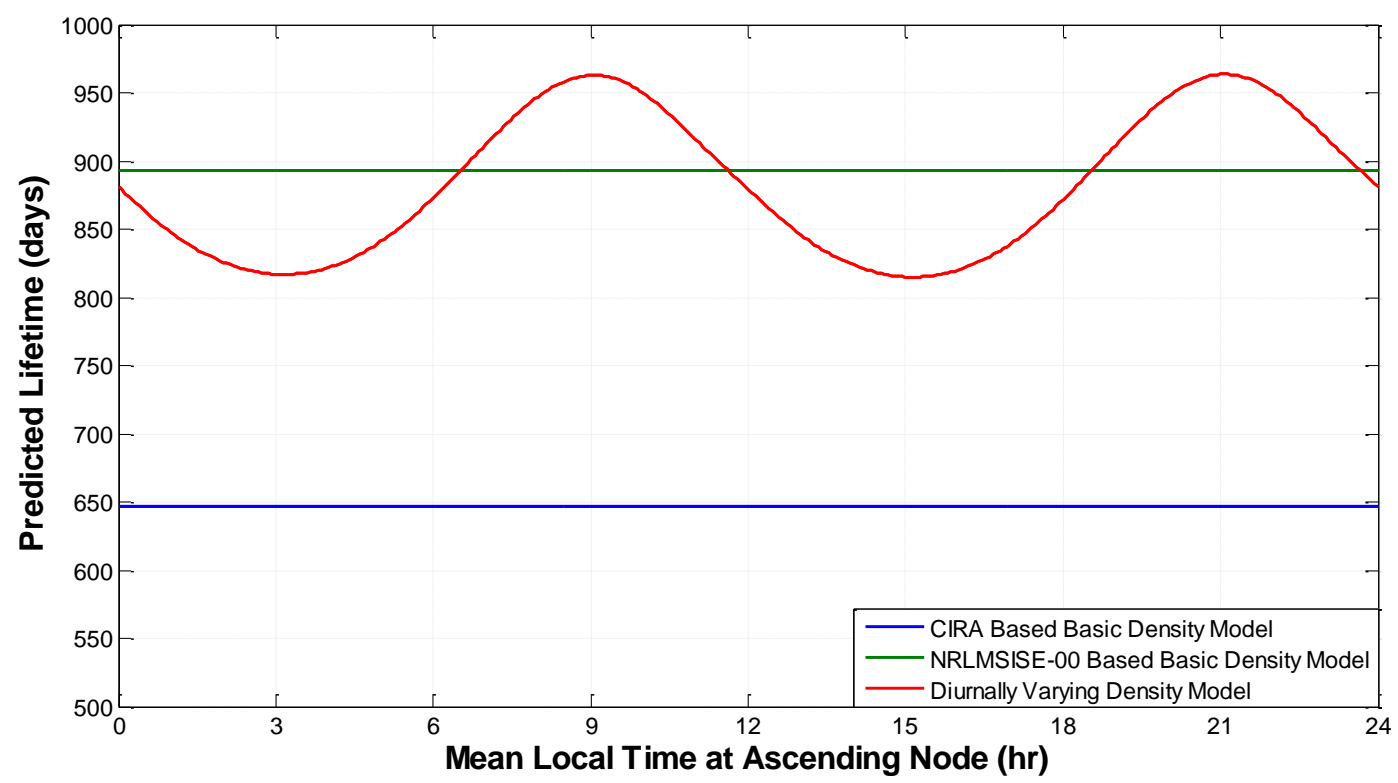

Figure 12. Comparison of lifetime predictions using various density models

It can be seen in Figure 12 that the orbit lifetime prediction can vary up to approximately 92 days under, and approximately 61 days over the mean lifetime when including the diurnal variation. This equates to approximately $-10.3 \%$ and $+6.8 \%$ difference. However more notable is the difference between the orbit lifetime predictions made using the CIRA based model and the NRLMSISE-00 based model; in this case the difference is approximately 247 days. This accounts for nearly a third of the orbit lifetime. 


\section{Conclusions}

The inclusion of a diurnally varying atmosphere model can produce up to $10.3 \%$ variations in the orbit lifetime predictions made for a sun-synchronous satellite using the authors' general perturbations analysis. Therefore when considering sun-synchronous satellites it is critical that the diurnal variation be considered. However, and perhaps more significantly it has been shown that the difference in orbit lifetime predictions made using the sphericallysymmetrical model derived from the CIRA density data as opposed to the spherically-symmetrical model derived from the NRLMSISE-00 density data accounts for a difference of approximately 247 days, which is nearly a third of the spacecraft's orbit lifetime. The CIRA based model has been shown in the authors' previous work to produce reliable orbit lifetime estimations, therefore it is concluded that the sample data set from NRLMSISE-00 used to build the diurnally varying atmospheric model is not representative and should be expanded. It is expected that when including a larger data set, the effect of the diurnal variation on the mean density will remain as it is shown in this paper; however the mean density is expected to shift to be more comparable to the mean density given by the CIRA based model. 


\section{Appendix A}

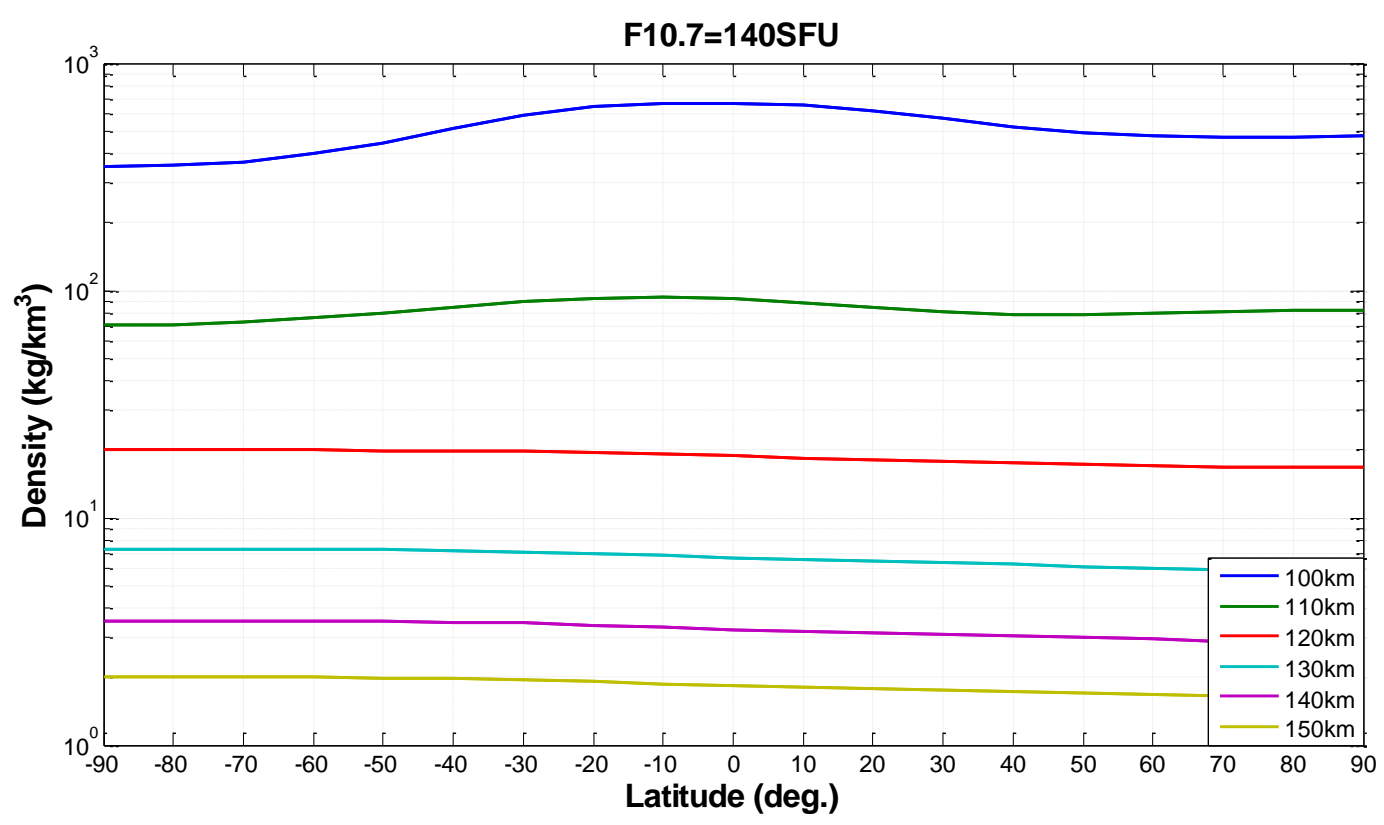

Atmospheric oblateness at moderate solar activity (N.B. logarithmic y-axis)

F10.7=230SFU

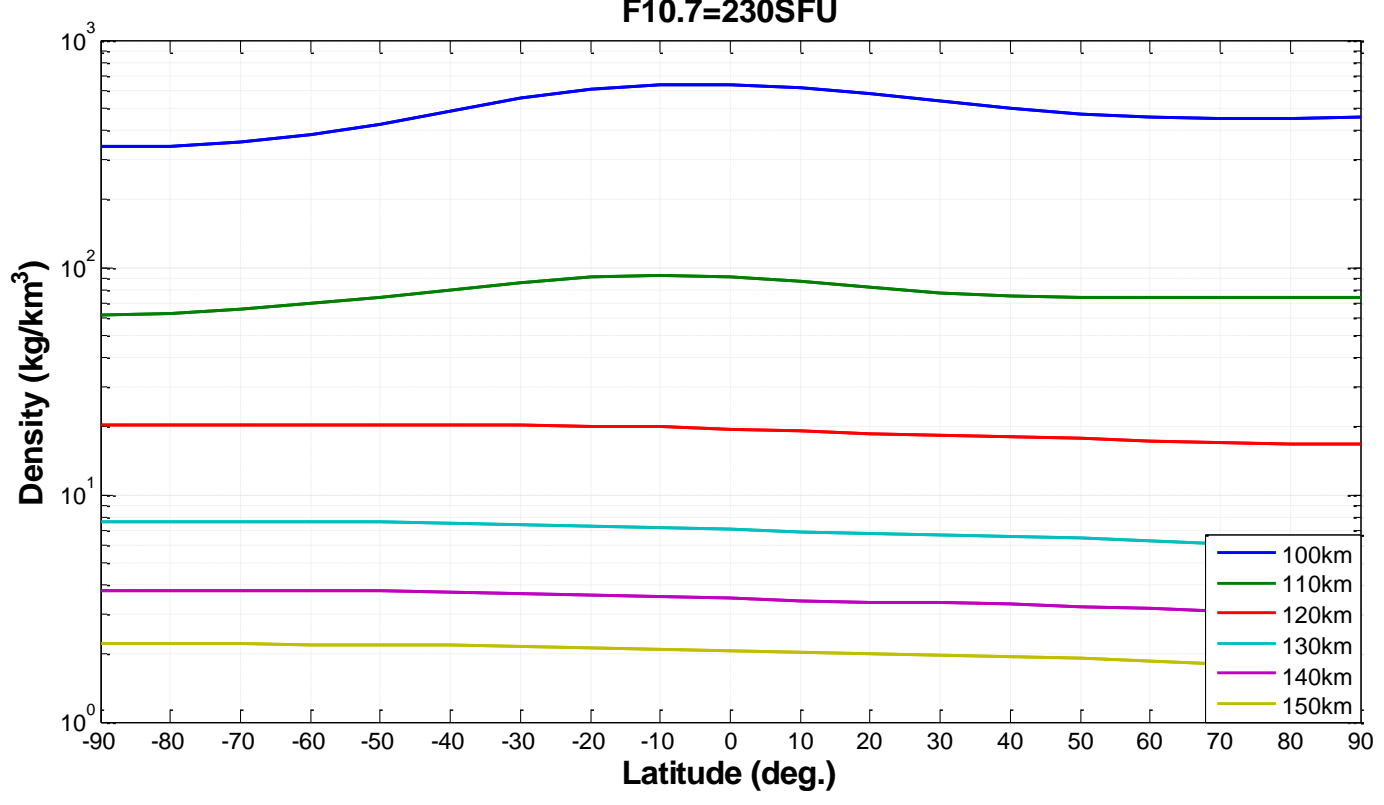

Atmospheric oblateness at high solar activity (N.B. logarithmic y-axis)

13

American Institute of Aeronautics and Astronautics 


\section{Appendix B}

F10.7 $=140 \mathrm{SFU}$

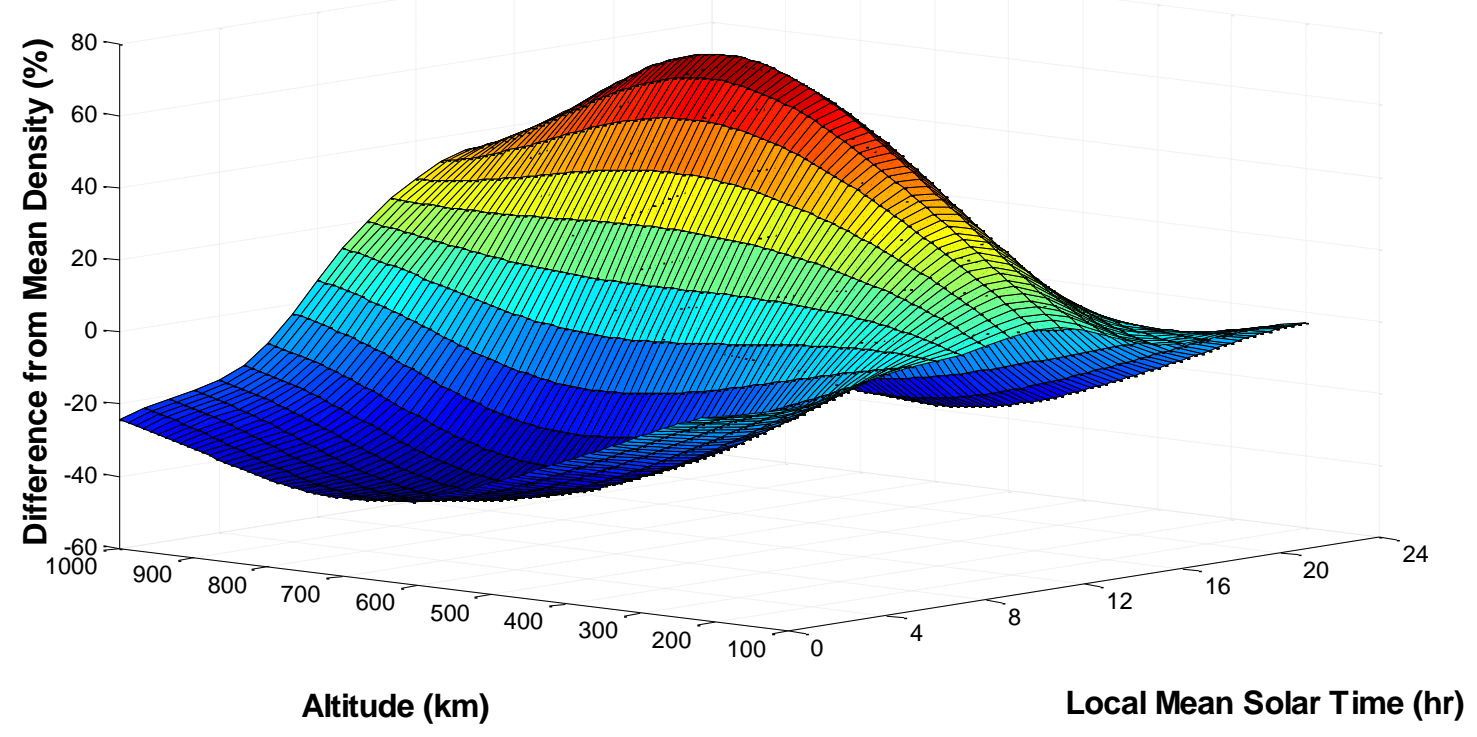

3D surface describing density variation at moderate solar activity due to the diurnal variation

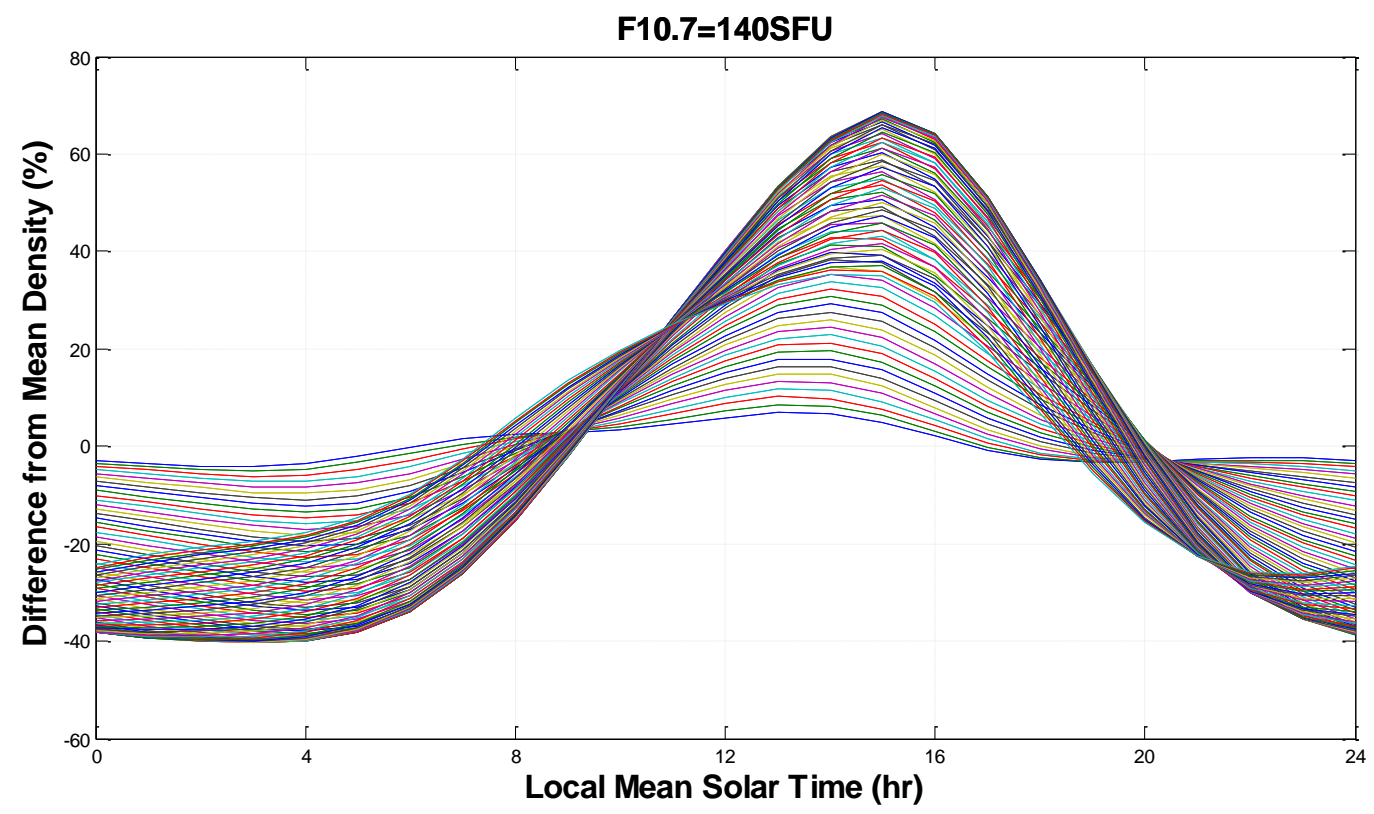

Altitude specific curves describing density variation at moderate solar activity due to the diurnal variation 


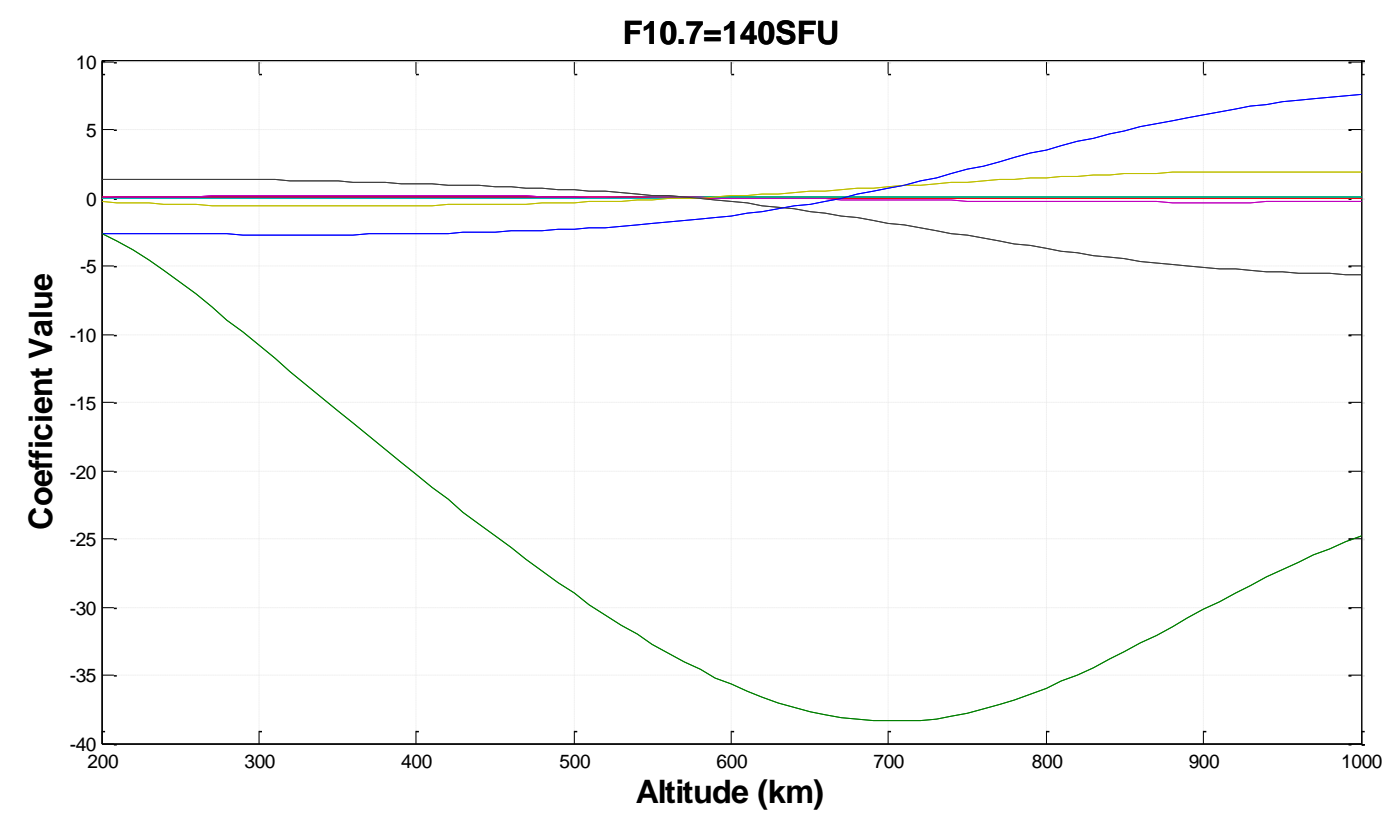

Variation due to altitude of coefficients for altitude specific curves from previous figure

\section{F10.7=230SFU}

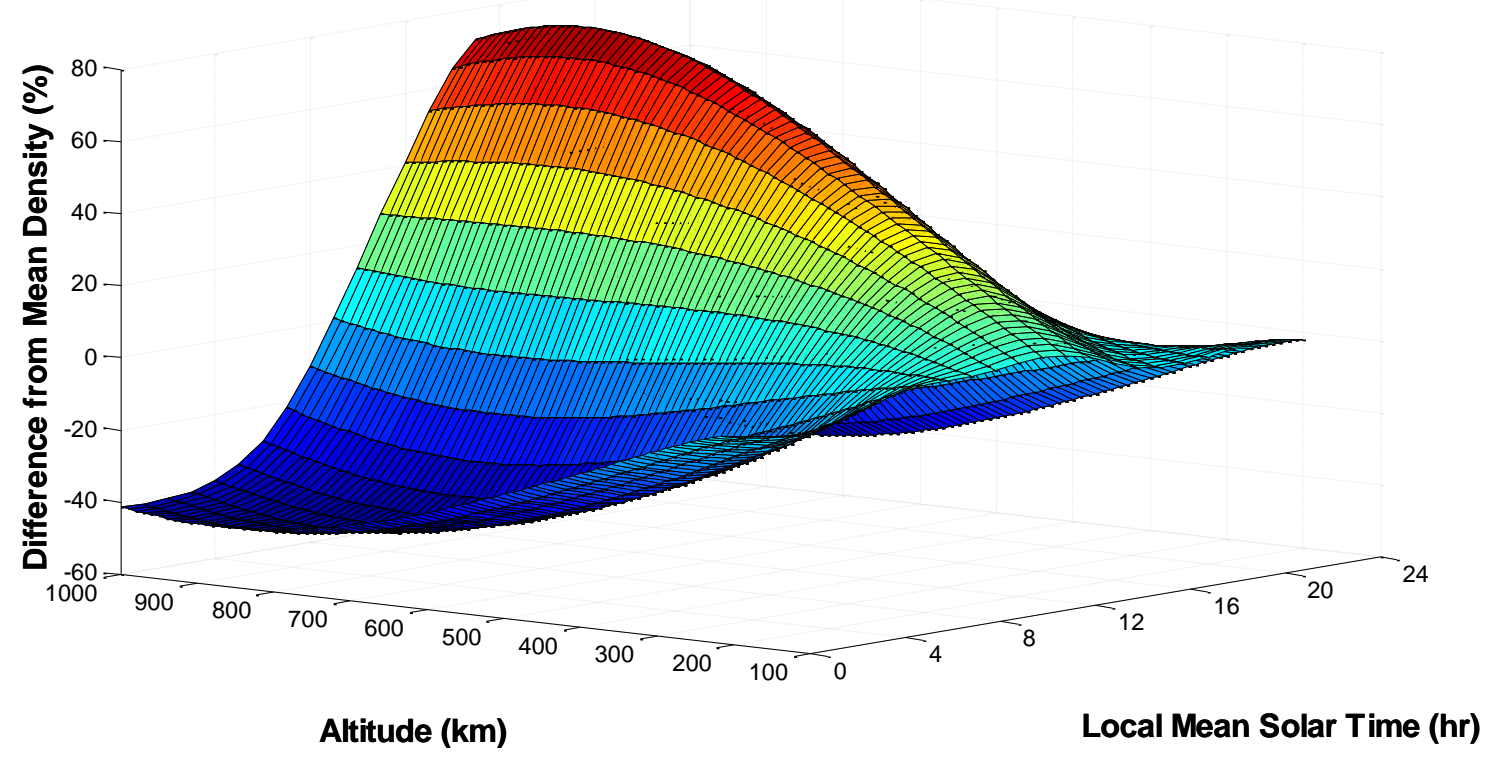

3D surface describing density variation at high solar activity due to the diurnal variation 


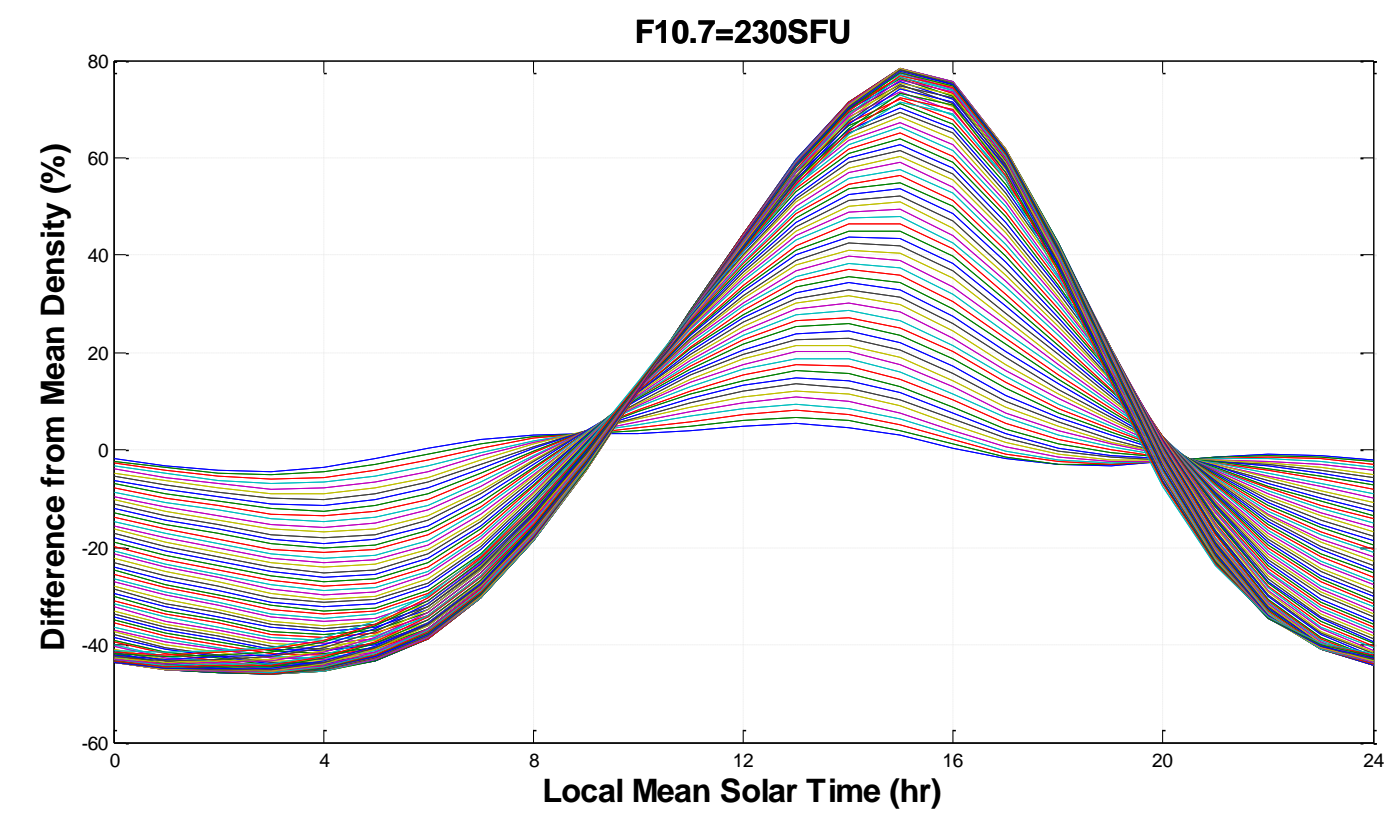

Altitude specific curves describing density variation at high solar activity due to the diurnal variation

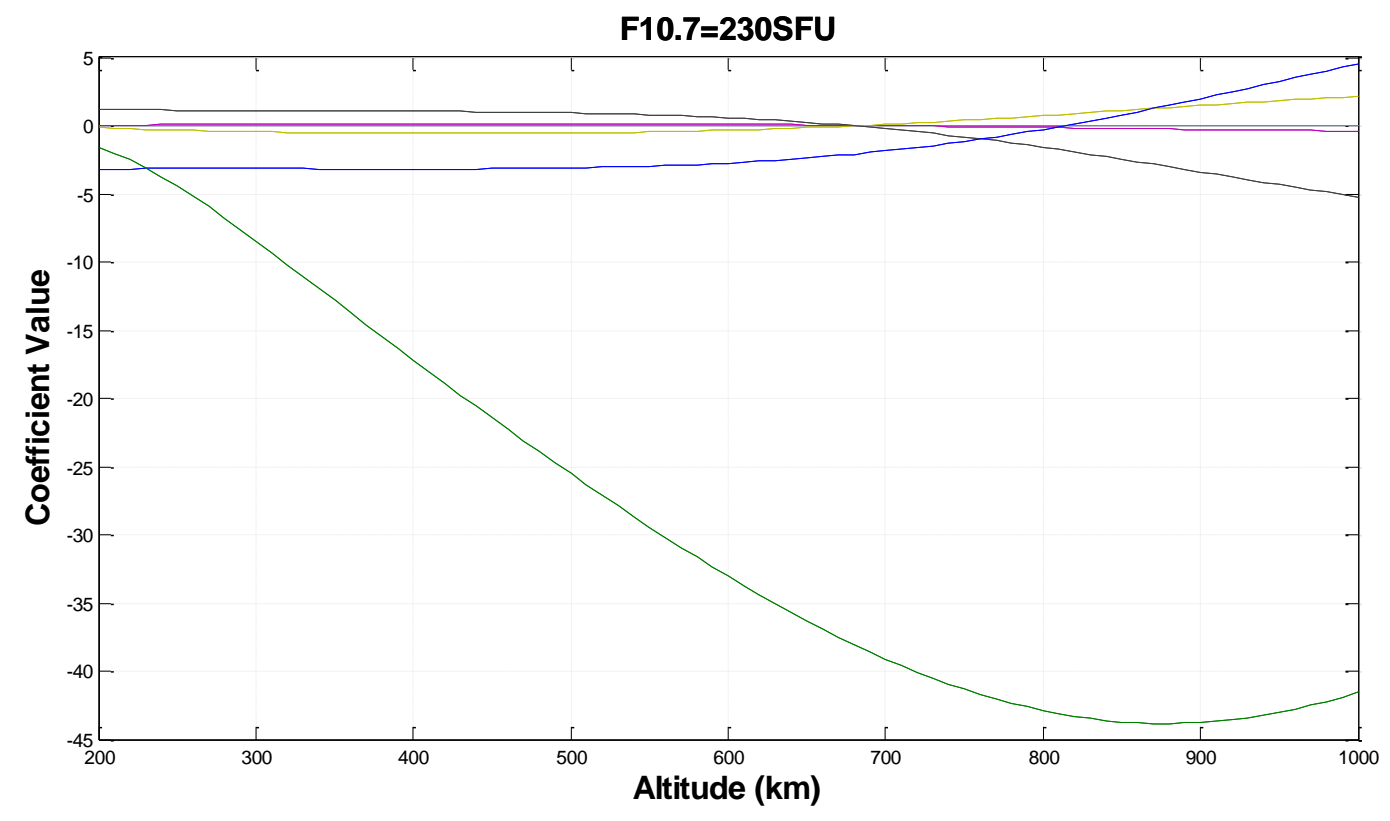

Variation due to altitude of coefficients for altitude specific curves from previous figure 


\section{Appendix C}

Coefficients for Eq. (2) and (3) for low solar activity

\begin{tabular}{|l|c|c|c|c|c|c|c|c|c|}
\hline & $c_{1}$ & $c_{2}$ & $c_{3}$ & $c_{4}$ & $c_{5}$ & $c_{6}$ & $c_{7}$ & $c_{8}$ & $c_{9}$ \\
\hline$p_{1}$ & $-2.052 \mathrm{E}-27$ & $9.988 \mathrm{E}-24$ & $-2.041 \mathrm{E}-20$ & $2.277 \mathrm{E}-17$ & $-1.512 \mathrm{E}-14$ & $6.125 \mathrm{E}-12$ & $-1.493 \mathrm{E}-09$ & $2.023 \mathrm{E}-07$ & $-1.165 \mathrm{E}-05$ \\
\hline$p_{2}$ & $1.813 \mathrm{E}-25$ & $-8.872 \mathrm{E}-22$ & $1.824 \mathrm{E}-18$ & $-2.049 \mathrm{E}-15$ & $1.37 \mathrm{E}-12$ & $-5.59 \mathrm{E}-10$ & $1.372 \mathrm{E}-07$ & $-1.872 \mathrm{E}-05$ & 0.001083 \\
\hline$p_{3}$ & $-6.242 \mathrm{E}-24$ & $3.078 \mathrm{E}-20$ & $-6.383 \mathrm{E}-17$ & $7.231 \mathrm{E}-14$ & $-4.879 \mathrm{E}-11$ & $2.01 \mathrm{E}-08$ & $-4.977 \mathrm{E}-06$ & 0.0006843 & -0.03979 \\
\hline$p_{4}$ & $1.049 \mathrm{E}-22$ & $-5.233 \mathrm{E}-19$ & $1.098 \mathrm{E}-15$ & $-1.259 \mathrm{E}-12$ & $8.596 \mathrm{E}-10$ & $-3.582 \mathrm{E}-07$ & $8.967 \mathrm{E}-05$ & -0.01244 & 0.7271 \\
\hline$p_{5}$ & $-8.78 \mathrm{E}-22$ & $4.451 \mathrm{E}-18$ & $-9.495 \mathrm{E}-15$ & $1.107 \mathrm{E}-11$ & $-7.685 \mathrm{E}-09$ & $3.252 \mathrm{E}-06$ & -0.0008246 & 0.1155 & -6.772 \\
\hline$p_{6}$ & $3.192 \mathrm{E}-21$ & $-1.668 \mathrm{E}-17$ & $3.662 \mathrm{E}-14$ & $-4.387 \mathrm{E}-11$ & $3.123 \mathrm{E}-08$ & $-1.351 \mathrm{E}-05$ & 0.003487 & -0.4937 & 28.84 \\
\hline$p_{7}$ & $-1.87 \mathrm{E}-21$ & $1.245 \mathrm{E}-17$ & $-3.269 \mathrm{E}-14$ & $4.492 \mathrm{E}-11$ & $-3.556 \mathrm{E}-08$ & $1.667 \mathrm{E}-05$ & -0.004566 & 0.6691 & -38.54 \\
\hline$p_{8}$ & $-5.076 \mathrm{E}-21$ & $1.916 \mathrm{E}-17$ & $-2.745 \mathrm{E}-14$ & $1.74 \mathrm{E}-11$ & $-3.019 \mathrm{E}-09$ & $-1.95 \mathrm{E}-06$ & 0.001158 & -0.2347 & 14.98 \\
\hline$p_{9}$ & $-5.007 \mathrm{E}-20$ & $2.248 \mathrm{E}-16$ & $-4.187 \mathrm{E}-13$ & $4.195 \mathrm{E}-10$ & $-2.466 \mathrm{E}-07$ & $8.758 \mathrm{E}-05$ & -0.01847 & 2.02 & -85.96 \\
\hline
\end{tabular}

Coefficients for Eq. (2) and (3) for moderate solar activity

\begin{tabular}{|l|c|c|c|c|c|c|c|c|c|}
\hline & $c_{1}$ & $c_{2}$ & $c_{3}$ & $c_{4}$ & $c_{5}$ & $c_{6}$ & $c_{7}$ & $c_{8}$ & $c_{9}$ \\
\hline$p_{1}$ & $3.95 \mathrm{E}-28$ & $-1.811 \mathrm{E}-24$ & $3.423 \mathrm{E}-21$ & $-3.456 \mathrm{E}-18$ & $2.025 \mathrm{E}-15$ & $-6.912 \mathrm{E}-13$ & $1.214 \mathrm{E}-10$ & $-5.692 \mathrm{E}-09$ & $-5.316 \mathrm{E}-07$ \\
\hline$p_{2}$ & $-3.496 \mathrm{E}-26$ & $1.61 \mathrm{E}-22$ & $-3.049 \mathrm{E}-19$ & $3.079 \mathrm{E}-16$ & $-1.797 \mathrm{E}-13$ & $6.064 \mathrm{E}-11$ & $-1.033 \mathrm{E}-08$ & $3.87 \mathrm{E}-07$ & $5.721 \mathrm{E}-05$ \\
\hline$p_{3}$ & $1.221 \mathrm{E}-24$ & $-5.658 \mathrm{E}-21$ & $1.077 \mathrm{E}-17$ & $-1.091 \mathrm{E}-14$ & $6.36 \mathrm{E}-12$ & $-2.131 \mathrm{E}-09$ & $3.549 \mathrm{E}-07$ & $-1.067 \mathrm{E}-05$ & -0.002268 \\
\hline$p_{4}$ & $-2.141 \mathrm{E}-23$ & $1.003 \mathrm{E}-19$ & $-1.929 \mathrm{E}-16$ & $1.971 \mathrm{E}-13$ & $-1.156 \mathrm{E}-10$ & $3.888 \mathrm{E}-08$ & $-6.507 \mathrm{E}-06$ & 0.0002048 & 0.03917 \\
\hline$p_{5}$ & $2.004 \mathrm{E}-22$ & $-9.56 \mathrm{E}-19$ & $1.876 \mathrm{E}-15$ & $-1.957 \mathrm{E}-12$ & $1.175 \mathrm{E}-09$ & $-4.068 \mathrm{E}-07$ & $7.275 \mathrm{E}-05$ & -0.003827 & -0.2163 \\
\hline$p_{6}$ & $-1.01 \mathrm{E}-21$ & $4.972 \mathrm{E}-18$ & $-1.011 \mathrm{E}-14$ & $1.1 \mathrm{E}-11$ & $-6.955 \mathrm{E}-09$ & $2.591 \mathrm{E}-06$ & -0.0005363 & 0.0505 & -1.482 \\
\hline$p_{7}$ & $2.693 \mathrm{E}-21$ & $-1.392 \mathrm{E}-17$ & $2.993 \mathrm{E}-14$ & $-3.476 \mathrm{E}-11$ & $2.378 \mathrm{E}-08$ & $-9.82 \mathrm{E}-06$ & 0.002385 & -0.3122 & 18.32 \\
\hline$p_{8}$ & $-2.588 \mathrm{E}-21$ & $1.42 \mathrm{E}-17$ & $-3.225 \mathrm{E}-14$ & $3.947 \mathrm{E}-11$ & $-2.843 \mathrm{E}-08$ & 0.0000124 & -0.003203 & 0.4475 & -28.52 \\
\hline$p_{9}$ & $-7.727 \mathrm{E}-22$ & $9.796 \mathrm{E}-18$ & $-3.347 \mathrm{E}-14$ & $5.341 \mathrm{E}-11$ & $-4.693 \mathrm{E}-08$ & $2.423 \mathrm{E}-05$ & -0.007333 & 1.107 & -64.42 \\
\hline
\end{tabular}

\section{Coefficients for Eq. (2) and (3) for high solar activity}

\begin{tabular}{|l|c|c|c|c|c|c|c|c|c|}
\hline & $c_{1}$ & $c_{2}$ & $c_{3}$ & $c_{4}$ & $c_{5}$ & $c_{6}$ & $c_{7}$ & $c_{8}$ & $c_{9}$ \\
\hline$p_{1}$ & $8.36 \mathrm{E}-29$ & $-4.316 \mathrm{E}-25$ & $9.268 \mathrm{E}-22$ & $-1.07 \mathrm{E}-18$ & $7.207 \mathrm{E}-16$ & $-2.842 \mathrm{E}-13$ & $5.594 \mathrm{E}-11$ & $-1.641 \mathrm{E}-09$ & $-5.311 \mathrm{E}-07$ \\
\hline$p_{2}$ & $-6.924 \mathrm{E}-27$ & $3.582 \mathrm{E}-23$ & $-7.688 \mathrm{E}-20$ & $8.827 \mathrm{E}-17$ & $-5.871 \mathrm{E}-14$ & $2.257 \mathrm{E}-11$ & $-4.137 \mathrm{E}-09$ & $-6.119 \mathrm{E}-09$ & $5.822 \mathrm{E}-05$ \\
\hline$p_{3}$ & $2.172 \mathrm{E}-25$ & $-1.131 \mathrm{E}-21$ & $2.432 \mathrm{E}-18$ & $-2.78 \mathrm{E}-15$ & $1.822 \mathrm{E}-12$ & $-6.776 \mathrm{E}-10$ & $1.116 \mathrm{E}-07$ & $5.912 \mathrm{E}-06$ & -0.00243 \\
\hline$p_{4}$ & $-3.106 \mathrm{E}-24$ & $1.647 \mathrm{E}-20$ & $-3.582 \mathrm{E}-17$ & $4.096 \mathrm{E}-14$ & $-2.641 \mathrm{E}-11$ & $9.395 \mathrm{E}-09$ & $-1.291 \mathrm{E}-06$ & -0.0002009 & 0.04796 \\
\hline$p_{5}$ & $1.756 \mathrm{E}-23$ & $-1.003 \mathrm{E}-19$ & $2.296 \mathrm{E}-16$ & $-2.694 \mathrm{E}-13$ & $1.727 \mathrm{E}-10$ & $-5.815 \mathrm{E}-08$ & $5.581 \mathrm{E}-06$ & 0.002412 & -0.4351 \\
\hline$p_{6}$ & $2.834 \mathrm{E}-24$ & $9.053 \mathrm{E}-20$ & $-3.828 \mathrm{E}-16$ & $5.911 \mathrm{E}-13$ & $-4.392 \mathrm{E}-10$ & $1.633 \mathrm{E}-07$ & $-1.825 \mathrm{E}-05$ & -0.006547 & 1.116 \\
\hline$p_{7}$ & $-1.598 \mathrm{E}-22$ & $3.367 \mathrm{E}-19$ & $2.948 \mathrm{E}-16$ & $-1.466 \mathrm{E}-12$ & $1.735 \mathrm{E}-09$ & $-1.032 \mathrm{E}-06$ & 0.0003398 & -0.05928 & 5.405 \\
\hline$p_{8}$ & $-1.41 \mathrm{E}-22$ & $1.194 \mathrm{E}-18$ & $-3.677 \mathrm{E}-15$ & $5.695 \mathrm{E}-12$ & $-4.983 \mathrm{E}-09$ & $2.593 \mathrm{E}-06$ & -0.0007945 & 0.1313 & -12.08 \\
\hline$p_{9}$ & $-4.278 \mathrm{E}-21$ & $2.258 \mathrm{E}-17$ & $-5.142 \mathrm{E}-14$ & $6.574 \mathrm{E}-11$ & $-5.137 \mathrm{E}-08$ & $2.511 \mathrm{E}-05$ & -0.007489 & 1.155 & -69.77 \\
\hline
\end{tabular}




\section{Appendix D}

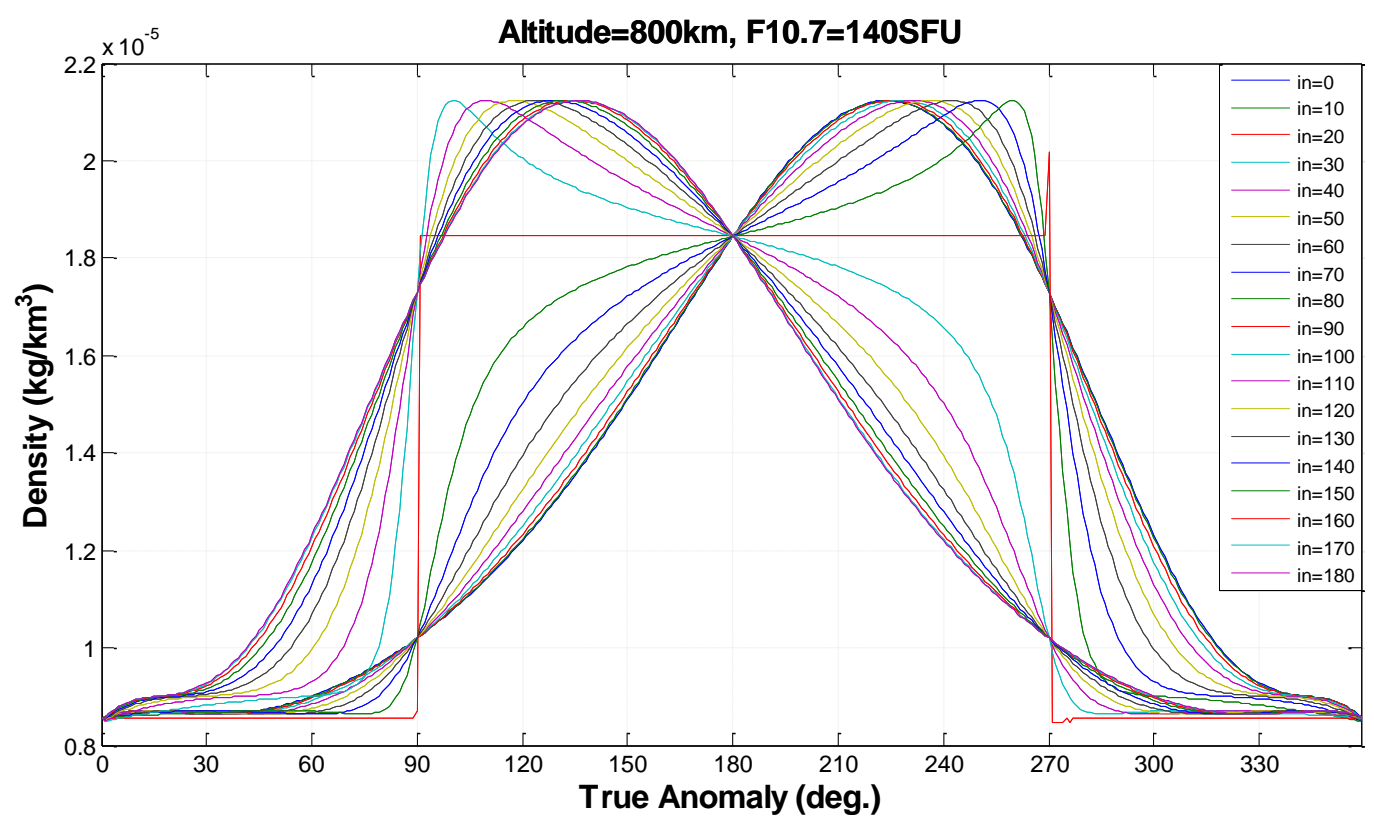

Change in density over 1 orbit revolution due to the diurnal variation for a satellite at $800 \mathrm{~km}$ altitude and various inclinations

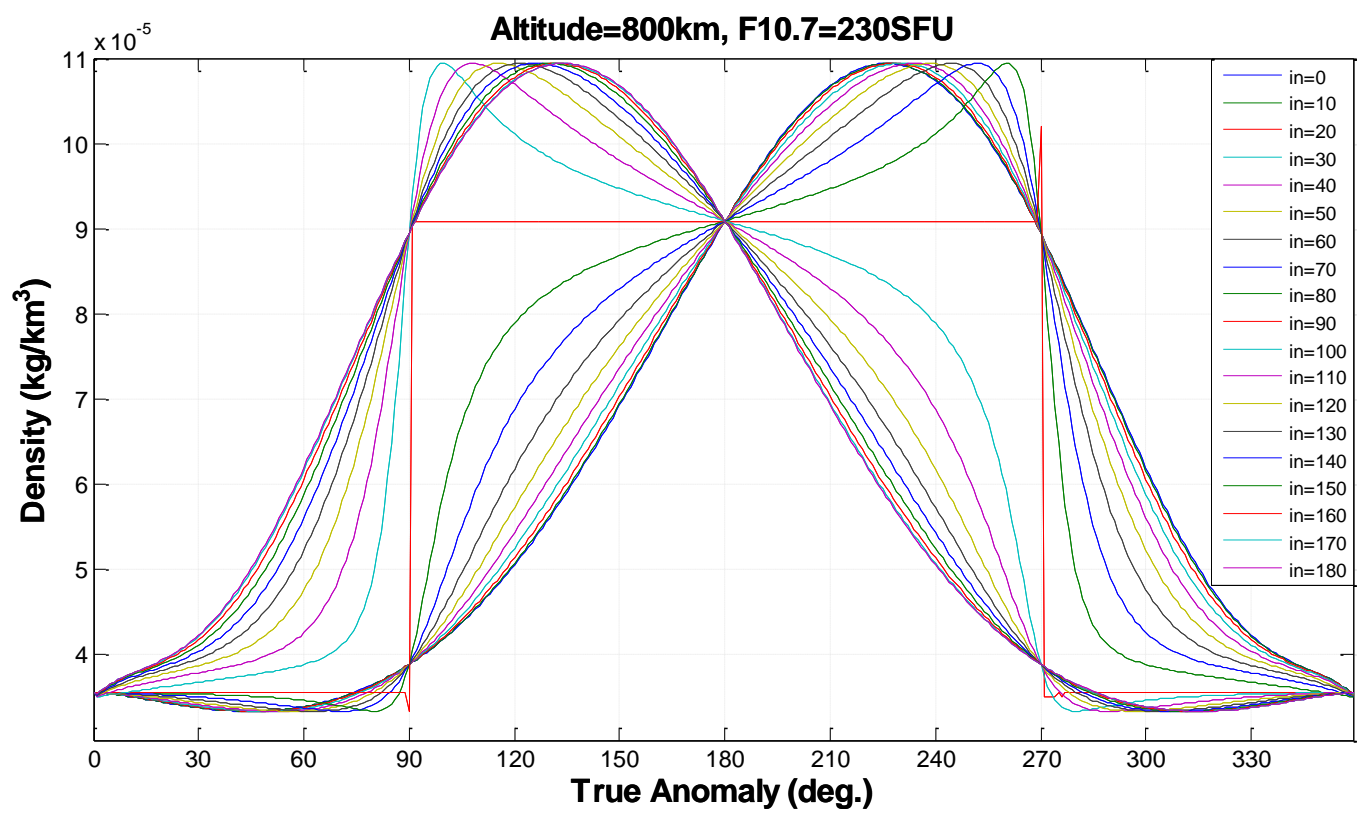

Change in density over 1 orbit revolution due to the diurnal variation for a satellite at $800 \mathrm{~km}$ altitude and various inclinations 


\section{Appendix E}

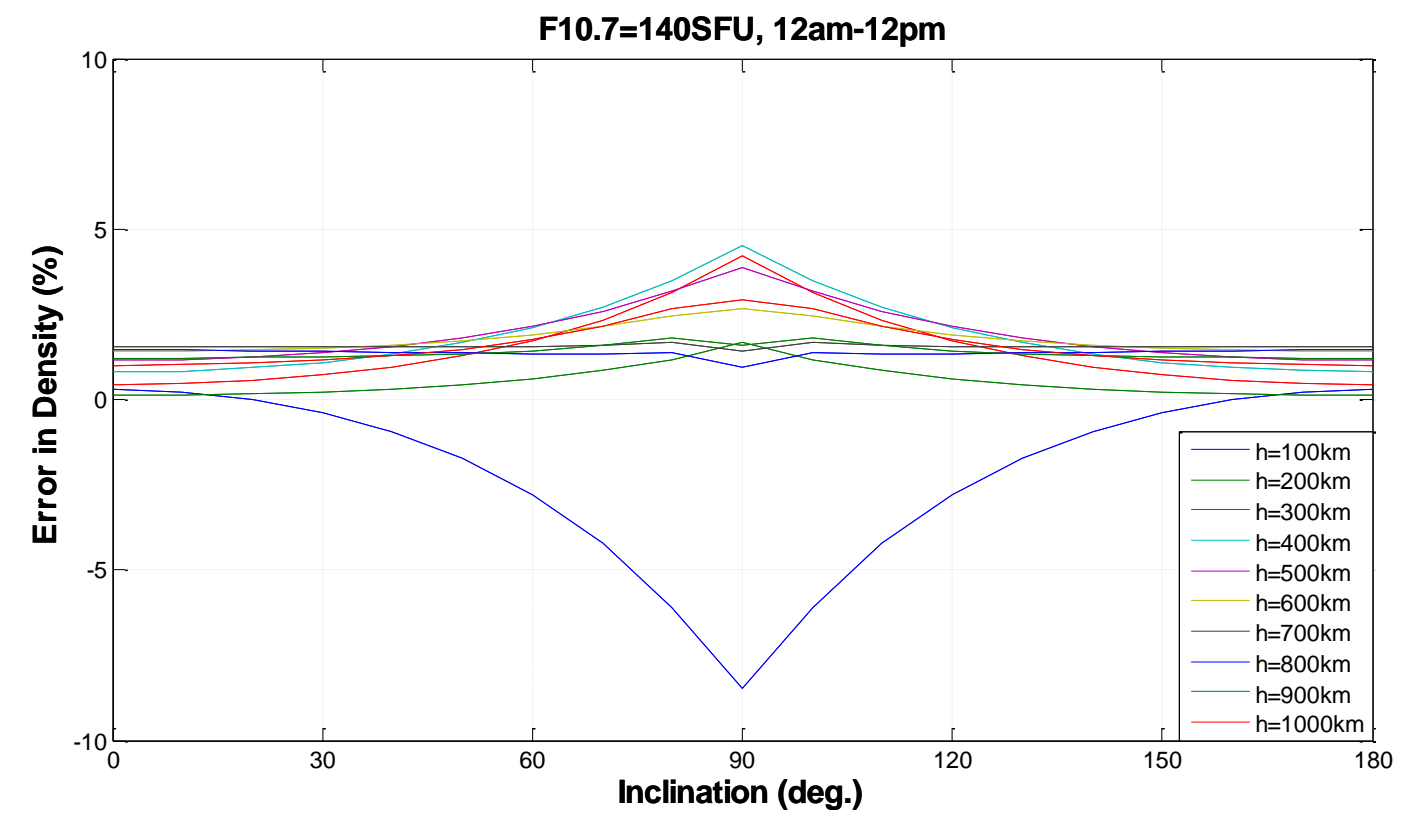

Error in density when comparing the mean density given by the diurnally varying atmospheric model and the mean density from the spherically-symmetrical atmospheric model for a 12am-12pm orbit

\section{F10.7=140SFU, 3am-3pm}

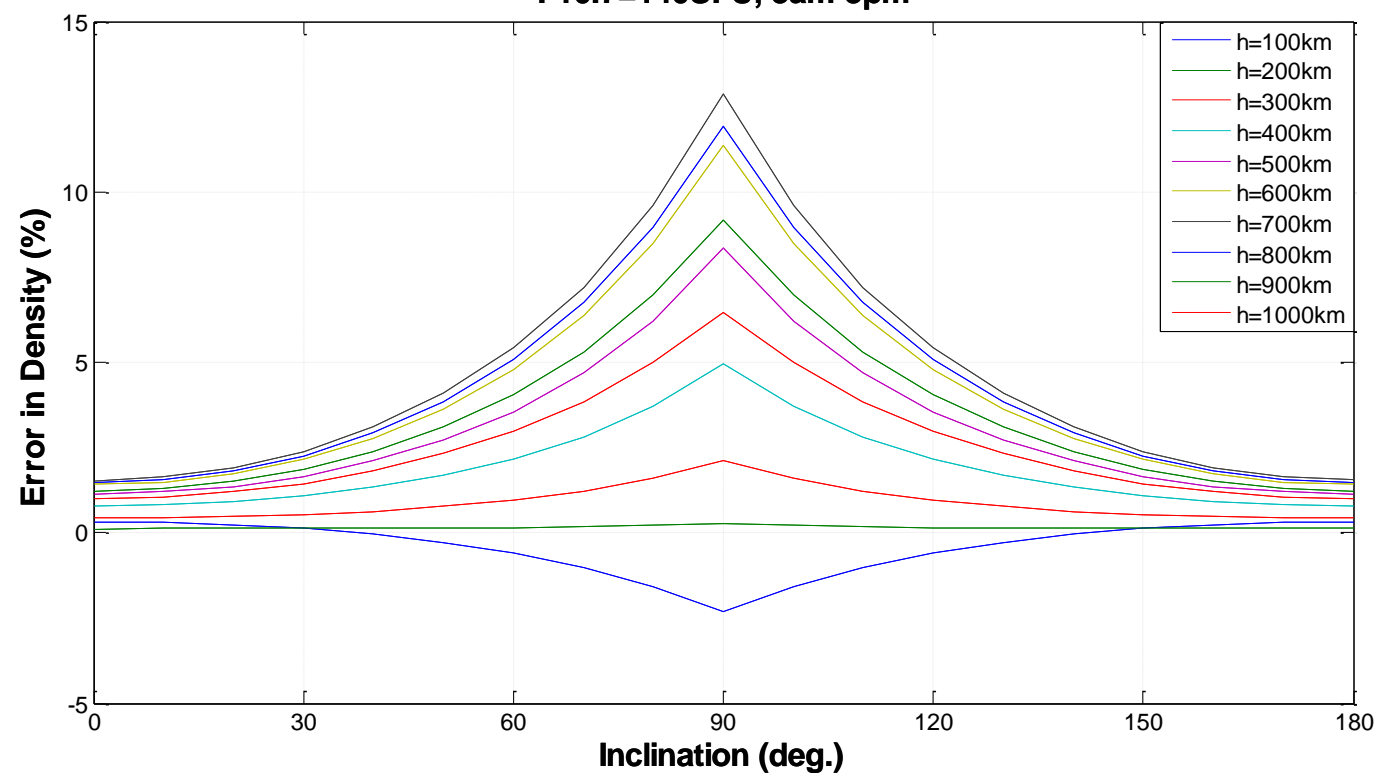

Error in density when comparing the mean density given by the diurnally varying atmospheric model and the mean density from the spherically-symmetrical atmospheric model for a 3am-3pm orbit 


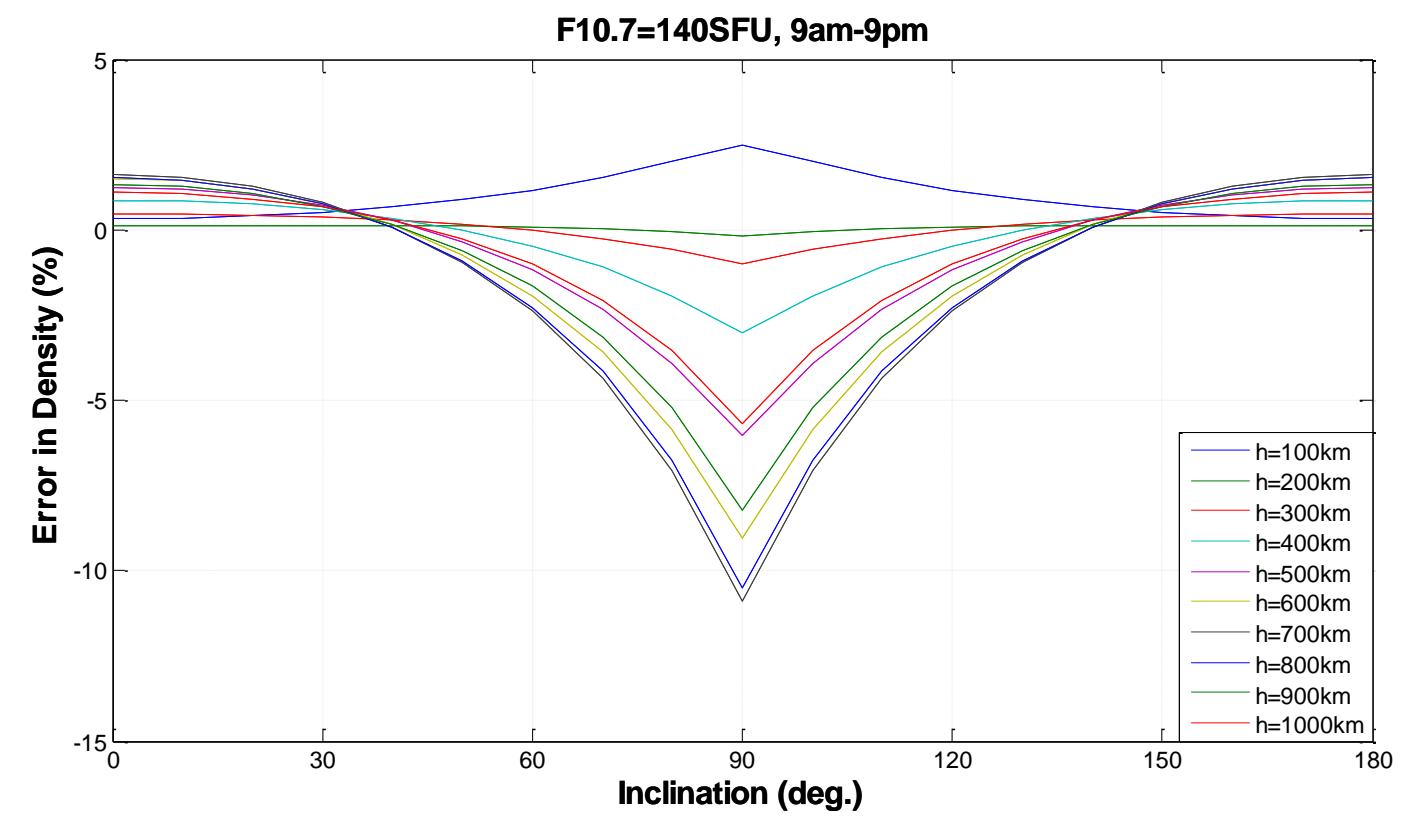

Error in density when comparing the mean density given by the diurnally varying atmospheric model and the mean density from the spherically-symmetrical atmospheric model for a 9am-9pm orbit

F10.7=230SFU, 12am-12pm

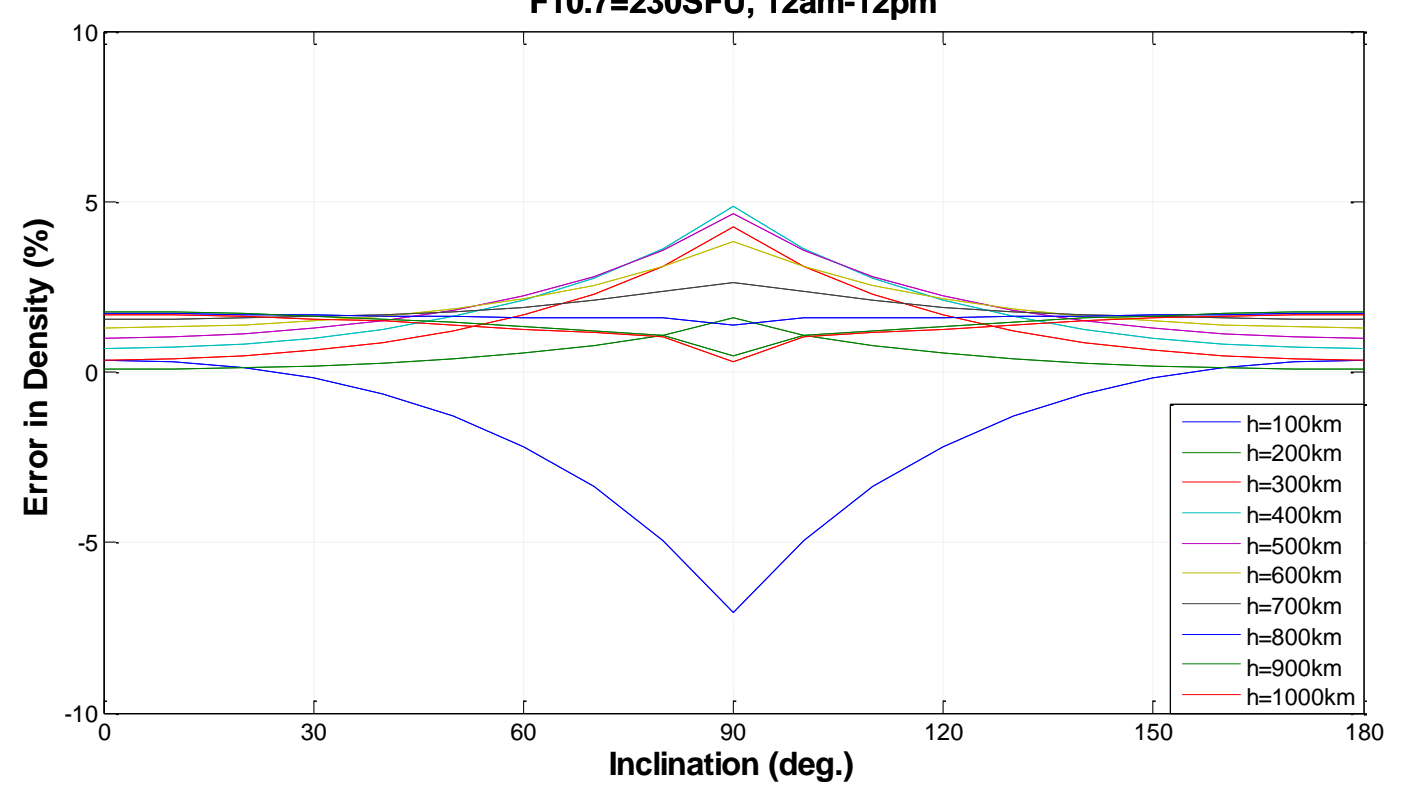

Error in density when comparing the mean density given by the diurnally varying atmospheric model and the mean density from the spherically-symmetrical atmospheric model for a 12am-12pm orbit 
F10.7=230SFU, 3am-3pm

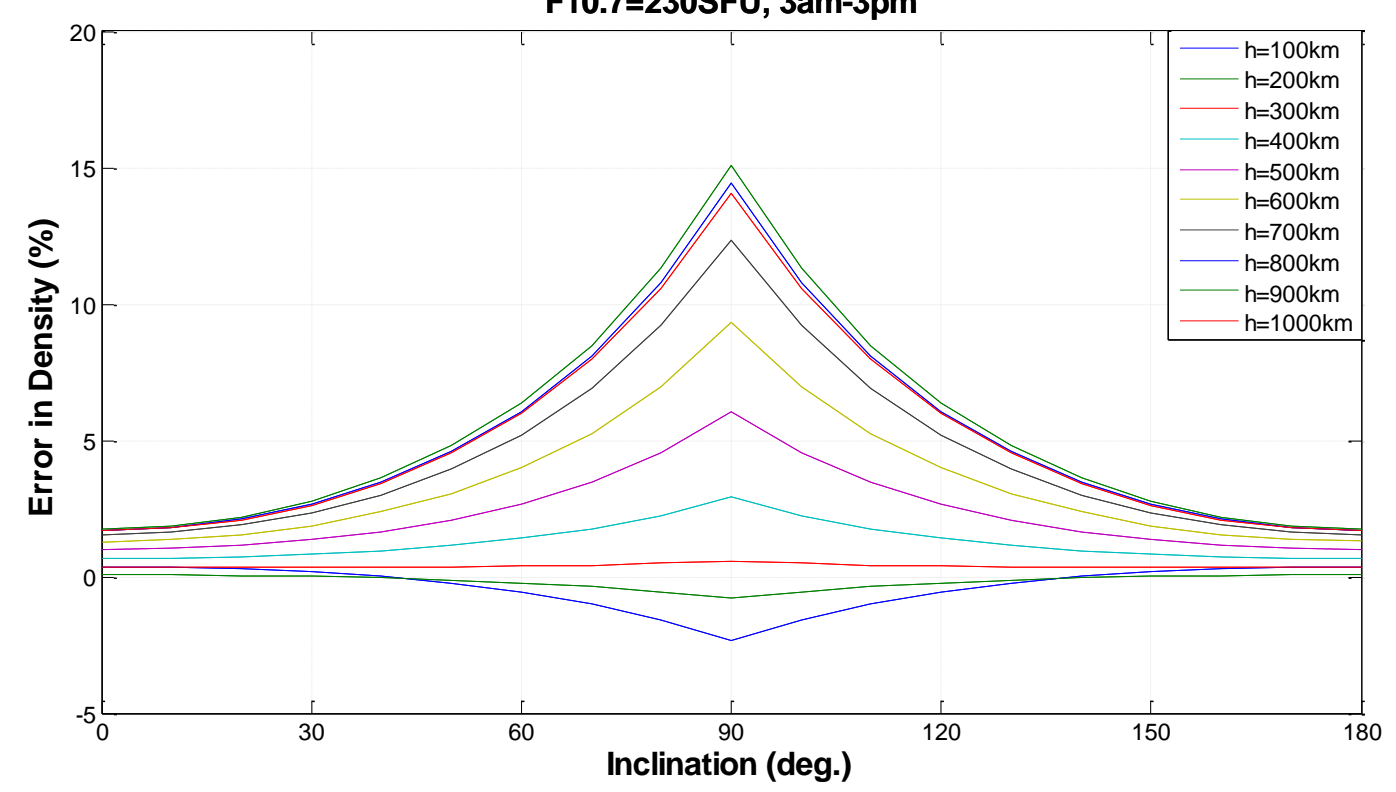

Error in density when comparing the mean density given by the diurnally varying atmospheric model and the mean density from the spherically-symmetrical atmospheric model for a 3am-3pm orbit

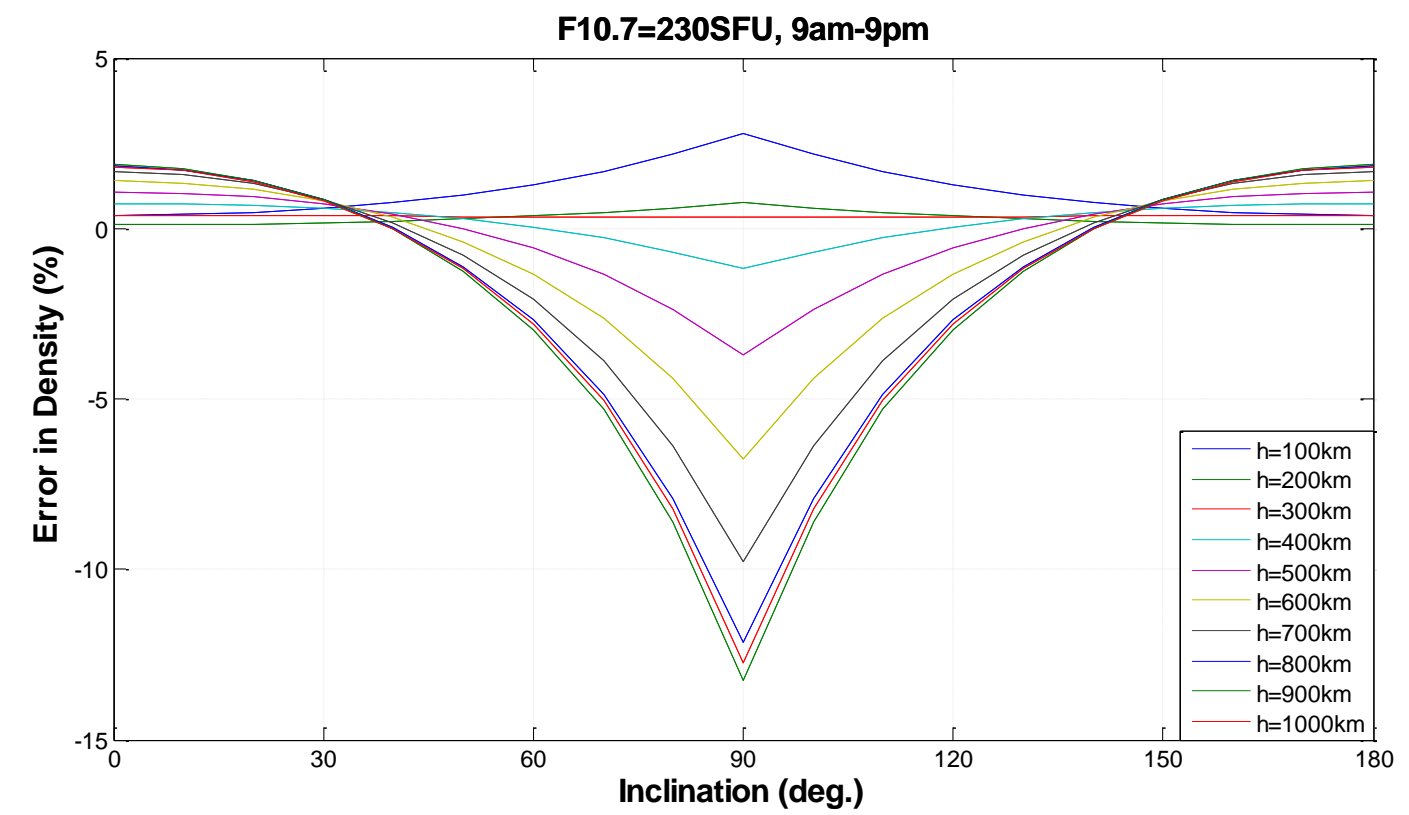

Error in density when comparing the mean density given by the diurnally varying atmospheric model and the mean density from the spherically-symmetrical atmospheric model for a 9am-9pm orbit 


\section{References}

Macdonald, M., and Badescu, V., eds., The International Handbook of Space Technology, Springer-Verlag Berlin Heidelberg, 2014.

Vallado, D. A., and McClain, W. D., Fundamentals of Astrodynamics and Applications, McGraw-Hill Inc., 1997.

Cook, G. E., King-Hele, D. G., and Walker, D. M. C., "The Contraction of Satellite Orbits under the influence of Air Drag I. With Sphericallly Symmetical Atmosphere," Proceedings of the Royal Society A: Mathematical, Physical and Engineering Sciences, vol. 257, 1960, pp. 224-249.

King-Hele, D. G., Satellite Orbits in an Atmosphere: Theory and Application, Glasgow: Blackie and Son Ltd, 1987.

Kerr, E., and Macdonald, M., "A General Perturbations Method for Spacecraft Lifetime Analysis Incorporating Solar Activity," Proceedings of the Royal Society Open Science (to be published) Kerr, E., and Macdonald, M., "A General Perturbations Method For Spacecraft Lifetime Analysis," 25th AAS/AIAA Space Flight Mechanics Meeting, Wiliamsburg, VA, USA: 2015, pp. 1-15.

Kerr, E., and Macdonald, M., "Improving the Accuracy of General Perturbations Methods for Spacecraft Lifetime Analysis," 66th International Astronautical Congress, Jerusalem, Isreal: 2015, pp. 1-6.

Kerr, E., and Macdonald, M., "Improving the Accuracy of Orbit Lifetime Analysis using Enhanced General Perturbation Methods," 26th AAS/AIAA Space Flight Mechanics Meeting, Napa, CA, USA: 2016, pp. 1-14. King-Hele, D. G., and Walker, D. M. C., "The Contraction of Satellite Orbits Under the Influence of Air Drag VIII. Orbital lifetime in an oblate atmosphere, when perigee distance is perturbed by odd zonal harmonics in the geopotential," Proceedings of the Royal Society A: Mathematical, Physical and Engineering Sciences, vol. 414, 1987, pp. 271-295.

Cook, G. E., King-Hele, D. G., and Walker, D. M. C., "The Contraction of Satellite Orbits Under the Influence of Air Drag II. With Oblate Atmosphere," Proceedings of the Royal Society A: Mathematical, Physical and Engineering Sciences, vol. 264, 1961, pp. 88-121.

Cook, G. E., and King-Hele, D. G., "The Contraction of Satellite Orbits under the Influence of Air Drag V. with Day-To-Night Variation in Air Density," Philosophical Transactions of the Royal Society of London A: Mathematical, Physical and Engineering Sciences, vol. 259, Dec. 1965, pp. 33-67.

Cook, G. E., and King-Hele, D. G., "The Contraction of Satellite Orbits Under the Influence of Air Drag VI. Near-Circular Orbits with Day-to-Night Variation in Air Density," Proceedings of the Royal Society A: Mathematical, Physical and Engineering Sciences, vol. 303, 1968, pp. 17-35.

Swinerd, G. G., and Boulton, W. J., "Contraction of Satellite Orbits in an Oblate Atmosphere with a Diurnal Density Variation," Proceedings of the Royal Society A: Mathematical, Physical and Engineering Sciences, vol. 383, Sep. 1982, pp. 127-145.

Sharma, R. K., "Contraction of satellite orbits using KS elements in an oblate diurnally varying atmosphere," Proceedings of the Royal Society A: Mathematical, Physical and Engineering Sciences, vol. 453, Nov. 1997, pp. 2353-2368.

Sharma, R. K., "A third-order theory for the effect of drag on Earth satellite orbits," Proceedings of the Royal Society A: Mathematical, Physical and Engineering Sciences, vol. 438, 1992, pp. 467-475.

Sharma, R. K., "Contraction of high eccentricity satellite orbits using K-S elements with air drag," Proceedings of the Royal Society A: Mathematical, Physical and Engineering Sciences, vol. 454, 1998, pp. 1681-1689.

Sharma, R. K., "Analytical approach using KS elements to near-Earth orbit predictions including drag," Proceedings of the Royal Society A: Mathematical, Physical and Engineering Sciences, vol. 433, 1991, pp. 121-130.

18 Commitee on Space Research, COSPAR International Reference Atmosphere - 2012, 2012. Naval Research Laboratory, NRLMSISE-00 Atmosphere Model [online database], URL: http://ccmc.gsfc.nasa.gov/modelweb/models/nrlmsise00.php Chao, C. C., Wilson, J. R., Mcvey, J. P., and Walterscheid, R. L., "Helium Discrepancy in the NRLMSISE2000 Density Model Detected Via CHAMP/GRACE Data and Decaying Sphere," 25th AAS/AIAA Space Flight Mechanics Meeting, Wiliamsburg, VA, USA: 2015, pp. 1-18. 